Research Article

\title{
Flight Recovery Method of Regional Multiairport Based on Risk Control Model
}

\author{
Quan Shao $\mathbb{D}^{1},{ }^{1}$ Mengxue Shao ${ }^{D},{ }^{1}$ Yunpeng Bin, ${ }^{2}$ Pei Zhu, ${ }^{1}$ and Yan Zhou \\ ${ }^{1}$ College of Civil Aviation, Nanjing University of Aeronautics and Astronautics, Nanjing 211100, China \\ ${ }^{2}$ Guangzhou Baiyun International Airport Co., Guangzhou 510080, China
}

Correspondence should be addressed to Quan Shao; shaoquan@nuaa.edu.cn

Received 14 October 2019; Accepted 4 February 2020; Published 29 April 2020

Academic Editor: Michele Guida

Copyright () 2020 Quan Shao et al. This is an open access article distributed under the Creative Commons Attribution License, which permits unrestricted use, distribution, and reproduction in any medium, provided the original work is properly cited.

\begin{abstract}
In the regional multiairport system, the contradiction between the limited operating resources and the large flight flow is serious, and the flight delays can easily lead to the occurrence of unsafe events. This paper investigates the abnormal flight recovery method in regional multiairport system based on risk control. The focus is to reschedule arrival-departure flights in real time with minimized delay time and risk probability. In this study, the risk about terminal area control and scene operation was considered in the analysis of the risk control model (RCM), which includes six key risk points: airspace control, flight conflict, ground service, apron support, ground control, and taxiing conflict. The mathematical model on flight recovery was constructed to solve minimized delay time and risk probability with MSINS (multistart algorithm with intelligent neighborhood selection). The data of a typical regional multiairport system in China were selected for experimental verification in order to compare the RCM with the traditional recovery model (TRM). The experimental results show that first, there are some hidden dangers in the traditional recovery methods of flight delay. Flight conflict and apron support are the risk points that need to be controlled most in the multiairport system. Secondly, for the effective solution with the shortest delay time, the RCM can reduce the overall operation risk of the system, but the flight delay time is a little longer. For the effective solution with the lowest risk probability, RCM can reduce the risk of system operation and the delay time of flights at the same time. Therefore, RCM can improve the security level of the system during abnormal flight recovery and ensure or even improve the recovery efficiency.
\end{abstract}

\section{Introduction}

Regional multiairport system (RMAS) refers to the cooperative operation of two or more airport groups in a certain economic area, optimizing the allocation of space resources and improving the utilization rate of airspace resources, which involves resource sharing and competition among multiple airports. RMAS is mainly distributed in economically developed areas and consists of major airports and secondary airports. As of 2016, there are more than 170 airport areas in the world, such as New York and Los Angeles in the United States [1]. In China, RMAS is developing rapidly, such as the Yangtze River Delta region and the Pearl River Delta region. Compared with the aviation in developed countries, the available civil airspace resources in
China are limited and the airspace structure is complex, and the mismatch between resource supply and flight demand is more obvious in the RMAS terminal area. In this kind of system, the flight normal rate of the main airport is below the national average flight normal rate for a long time.

The flight flow in RMAS is relatively large. When largescale flight delays are caused by unexpected events, due to the limited space-time resources and the saturation of terminal resources, the ground support work and air traffic control personnel are operating at high load. The flight adjustable redundancy is small, the safety control pressure is large, and the system security has a restrictive relationship with the flight recovery. The unsafe factors in terminal area and scene operation are increased, which easily leads to the occurrence of unsafe incidents and poses 
a great threat to the safe operation of the flight. For example, at around 16:00 on August 9, 2012, the collision between the tail wing and the right wing of two aircrafts at Shanghai Pudong International Airport occurred during the resumption of a large number of abnormal flights after Typhoon "Sea Anemone." As many as 1172 flights took off and landed at the airport on that day. On the other hand, increasing the risk control of terminal area and scene operation in the process of abnormal flight recovery can improve the security level of the system. Therefore, this paper considers the airspace control and flight conflict in the terminal area, as well as the ground support, apron support, ground control, and taxiing conflict in scene operation as the risk control points, to study the abnormal flight recovery method based on risk control.

Scholars have conducted extensive research on abnormal flight recovery. Aiming at the abnormal flight recovery problem of a single airport, Teodorović and Guberinić creatively proposed a heuristic algorithm that solves the route of each aircraft as a network flow problem using the branch-and-bound algorithm [2]. Cao and Kanafani proposed a quadratic $0-1$ programming model for the integrated decision-making problem of flight cancellation and delay, which is solved by an approximate linear programming algorithm of multidimensional search $[3,4]$. Argüello et al. established the constraint model and proposed a greedy random adaptive search program (GRASP) to solve the problem [5]. The constraints of the mathematical model established in the above studies are mainly flight coverage, resource balance, aircraft allocation constraints, and so on, and the objective function is to minimize the delay cost or total delay time. Rosenberger et al. [6], Eggenberg et al. [7], Bisaillon et al. [8], and Liang et al. [9] incorporated maintenance plan into constraint condition and used heuristic algorithm to solve it. Further, in order to reduce the limitation of optimization decision, Rosenberger et al. [6], Petersen et al. [10], Sinclair et al. [11], and Zhang et al. [12] added constraints such as airport capacity limit, flow balance, and flight section constraint. In addition, they solved the problem of integrated recovery of abnormal flights combining the problem of crew recovery and the problem of passenger recovery.

There is not much research on flight recovery in a multiairport system. Kleinman et al. discussed how to use simultaneous perturbed random approximation algorithms (SPSA) and SIMMOD to deal with delay cost measurement and generate optimal gate waiting schedule [13]. In order to avoid flight delay, many scholars have studied the problem of cooperative scheduling optimization in RMAS. Saraf et al. have analyzed the ability of FCFS, joint scheduling, and priority assignment to reduce delay [14]. Capozzi et al. proposed a mixed integer linear programming method to solve the problem of air traffic scheduling and route selection in RMAS [15]. Based on the characteristics of the multiairport system, some studies [16-19] comprehensively considered the constraints of wake interval, runway operation mode, and location constraints, established a collaborative scheduling model, and used algorithms (GA [16], SA
[17], NSGA-II [18], and FS-MOPSO [19]) to solve the models.

To sum up, in previous studies, various methods and models have been proposed to optimize operating resources or improve the recovery efficiency of abnormal flights, but less consideration has been given to the impact of risk factors such as personnel load and scene operation on abnormal flight recovery. These risk factors do have complex interactions with flight recovery [20-22] and need to be further quantified. In this paper, we consider the risk factors in the terminal area and scene operation, establish a recovery model of quantitative risk control, and select the operational data of typical RMAS to study the regional multiairport abnormal flight recovery method based on risk control. In the case of the traditional recovery method (TRM), this paper analyzes the risk points that need to be controlled most in the multiairport system under various delays so as to provide technical support for improving the recovery efficiency of abnormal flights and ensuring the safe operation of the airport.

The rest of the paper is organized follows. Section 2 describes the abnormal flight recovery model with risk control and risk assessment of the risk control points. Section 3 briefly introduces the structure of MSINS. Case study and results analysis are reported in Section 4, followed by the conclusion and discussion of future research directions in Section 5.

\section{The Mathematical Model}

In the context of abnormal flight recovery at RMAS, the problem is to reschedule arrival-departure flights under basic constraints and risk control constraints. Suppose that the predicted runway time, the arrival-departure route, and the predicted allocation of gates are known during the RMAS preoptimization period. Assume that the flight time and taxiing time of the flight can be calculated according to the type of aircraft, route distance, and taxiing path. Moreover, we assumed that the estimated take-off or landing time can be used to calculate the time for the flight to pass through the arrival-departure location and the ground taxiing conflict point. The abnormal flight recovery model of RMAS based on risk control is constructed as follows.

2.1. Objective Function. The optimization of the regional multiairport abnormal flight recovery model based on risk control is to minimize the sum of all flight delays and minimize the sum of risk probabilities in all periods.

$$
\begin{aligned}
& \min \left(\sum_{i \in F} \mathrm{DT}_{i}\right), \\
& \min \left(\sum_{t \in T} \operatorname{Risk}(t)\right) .
\end{aligned}
$$

The delay time and the total risk can be calculated as equations (2) and (3), respectively. 


$$
\begin{aligned}
\mathrm{DT}_{i}= & \mathrm{ET}_{i}-\mathrm{ST}_{i} \\
\operatorname{Risk}(t)= & \sum_{s \in S} \chi_{s}^{W} \operatorname{Risk}_{s}^{W}(t)+\sum_{s \in S} \chi_{s}^{C} \operatorname{Risk}_{s}^{C}(t)+\sum_{u \in U} \chi_{u}^{U} \operatorname{Risk}_{u}^{U}(t) \\
& +\sum_{u \in U, r \in L^{r}} \chi_{u}^{U_{r}} \operatorname{Risk}_{u}^{U_{r}}(t)+\sum_{u \in U} \chi_{u}^{W U} \operatorname{Risk}_{u}^{W U}(t) \\
& +\sum_{u \in U} \chi_{u}^{C O} \operatorname{Risk}_{u}^{C O}(t), \quad \forall t \in T
\end{aligned}
$$

where $\mathrm{DT}_{i}$ represents the delay time of flight $i \mathrm{ET}_{i}$ and $\mathrm{ST}_{i}$ are the target runway time and estimated runway time of the flight $i$, respectively;Risk represents the comprehensive risk probability; $\operatorname{Risk}_{s}^{W}$ and $\operatorname{Risk}_{s}^{C}$ represent risk probability of controller workload and aircraft collision frequency in sector $s$, respectively; $\operatorname{Risk}_{u}^{U}$, $\operatorname{Risk}_{u}^{\mathrm{WU}}$, and $\operatorname{Risk}_{u}^{\mathrm{CO}}$ represent the risk probability of ground service capability, ground controller workload, and aircraft taxiing conflict in airport $u$, respectively; $\operatorname{Risk}_{u}^{U_{r}}$ is the risk probability of service capability in the $r$ apron area of airport $u$; $U, T$, and $S$ are the set of all airports, all available time periods for flight optimization, and all sectors in the system, respectively; and $\chi_{s}^{W}, \chi_{s}^{C}, \chi_{u}^{U}, \chi_{u}^{U_{r}}, \chi_{u}^{\mathrm{WU}}$, and $\chi_{u}^{\mathrm{CO}}$ are the weights of various risks.

2.2. Constraints. Based on the interval constraints and capacity constraints of the traditional recovery model (equations (4)-(11)), the risk control conditions (equations (12)-(17)) are added to the model proposed in this paper. Note that $F, R_{u}$, and LP are the set of flights to be optimized, all runways, and all arrival-departure locations, respectively. The constraints are as follows:

$$
\text { \% s.t. } \quad\left(\mathrm{FA}_{u}(t), \mathrm{FD}_{u}(t)\right) \in \mathrm{CR}_{u}(t), \quad \forall u \in U, \forall t \in T,
$$

$$
\mathrm{FA}_{u}^{g}(t)-\mathrm{FD}_{u}^{g}(t) \leq \mathrm{CP}_{u}^{g}(t), \quad \forall g \in \mathrm{MP}, \forall u \in U, \forall t \in T,
$$

$$
\mathrm{FS}_{s}(t) \leq \mathrm{CS}_{s}(t), \quad \forall s \in S, \forall t \in T
$$

$$
\begin{aligned}
\lambda_{i, j} \eta_{i, j} \gamma_{i, j}\left(\mathrm{ET}_{i}+\sigma_{i, j}\right) \leq \mathrm{ET}_{j}, \quad \forall i, j \in F \\
\omega_{i, j} \rho_{i, j}\left(\mathrm{LPT}_{i}+\delta_{i, j}\right) \leq \mathrm{LPT}_{j}, \quad \forall i, j \in F,
\end{aligned}
$$

$\% \lambda_{i, j} \theta_{i, j, m, n}\left(\mathrm{ET}_{i}+v_{i, j, m, n}\right) \leq \mathrm{ET}_{j}, \quad \forall i, j \in F, \forall m, n \in R_{u}, \forall u \in U$

$$
\begin{aligned}
\lambda_{i, j} \gamma_{i, j}\left(\mathrm{ET}_{i}+l_{i}\right) \leq \mathrm{ET}_{j}, \quad \forall i, j \in F, \\
\mathrm{LT}_{i} \leq \mathrm{ET}_{i} \leq \mathrm{UT}_{i}, \quad \forall i \in F, \\
\operatorname{Risk}_{s}^{W}(t) \leq \mathrm{Risk}_{\text {level }}^{W}, \quad \forall s \in S, \forall t \in T,
\end{aligned}
$$

$$
\begin{gathered}
\operatorname{Risk}_{s}^{C}(t) \leq \operatorname{Risk}_{\text {level }}^{C}, \quad \forall s \in S, \forall t \in T, \\
\operatorname{Risk}_{u}^{U}(t) \leq \text { Risk level }_{\text {lel }}^{U}, \quad \forall u \in U, \forall t \in T, \\
\operatorname{Risk}_{u}^{U_{r}}(t) \leq \text { Risk }_{\text {level }}^{U_{r}}, \quad \forall u \in U, \forall r \in L^{r}, \forall t \in T, \\
\operatorname{Risk}_{u}^{\mathrm{WU}}(t) \leq \operatorname{Risk}_{\text {level }}^{\mathrm{WU}}, \quad \forall u \in U, \forall t \in T, \\
\operatorname{Risk}_{u}^{\mathrm{CO}}(t) \leq \operatorname{Risk}_{\text {level }}^{\mathrm{CO}}, \quad \forall u \in U, \forall t \in T .
\end{gathered}
$$

Equation (4) represents runway capacity constraints, which mean that arrival flow $\mathrm{FA}_{u}(t)$ and departure flow $\mathrm{FD}_{u}(t)$ at the airport $u$ during the period $t$ should meet the capacity constraint curve $\mathrm{CR}_{u}(t)[21]$. Equation (5) represents gate resource constraints, which require that the flight demand for type $g$ gates must not be greater than the capacity constraint $\left(\mathrm{CP}_{u}^{g}(t)\right)$. Equation (6) represents the sector capacity constraints, which require that arrivaldeparture flight flow of a sector $s$ during period $t\left(\mathrm{FS}_{s}(t)\right)$ must satisfy the capacity $\mathrm{CS}_{s}(t)$. Equation (9) represents runway-related interval constraints, which require that the successive aircrafts using the relevant runway must meet certain safety separation criteria $\left(\nu_{i, j, m, n}\right)$. Equation (11) represents time window constraints, which mean that the target runway time $\left(\mathrm{ET}_{i}\right)$ is within the limits of the upper $\left(\mathrm{UT}_{i}\right)$ and lower $\left(\mathrm{LT}_{i}\right)$ time windows. Equations (7)-(10) are the constraints about runway wake interval, the arrival-departure locations interval, and using runway interval. Equations (12)-(17) make sure that each risk probability is below its corresponding acceptable level

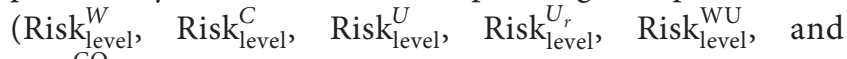
$\left.\operatorname{Risk}_{\text {level }}^{\mathrm{CO}}\right)$.

In addition, at airport $u$ during period $t, \mathrm{FA}_{u}^{g}(t)$ and $\operatorname{FD}_{u}^{g}(t)$ are arrival and departure flight flow of the type $g$ gates; $\mathrm{CP}_{u}^{g}(t)$ is the initial remaining amount of type $g$ gates. $\sigma_{i, j}$ is runway wake safety interval criterion for flights $i$ and $j . \lambda_{i, j}$ is equal to 1 if flight $i$ uses the runway before flight $j$; otherwise, it is zero. Similarly, $\eta_{i, j}$ is equal to 1 if flights $i$ and $j$ are both arrival or departure flights. $\gamma_{i \cdot j}$ is equal to 1 if flight $i$ uses the same runway as flight $j . \mathrm{LPT}_{i}$ is the target transit time of flight $i$ through the arrival-departure location. $\delta_{i, j}$ is the safety interval criterion that should be met when flights $i$ and $j$ pass the same arrivaldeparture locations. $\omega_{i, j}$ is equal to 1 if flight $i$ passes the arrival-departure location before flight $j$; otherwise, it is zero. $\rho_{i, j}$ is equal to 1 if flights $i$ and $j$ use the same arrivaldeparture location. Let $l_{i}$ be runway time for flight $i$. If there ,are runway-related operational impacts on flight $i$ using runway $m$ and flight $j$ using runway $n, \theta_{i, j, m, n}$ is equal to 1 and $v_{i, j, m, n}$ is runway-related safety separation criterion that should be met.

2.3. Risk Assessment of Regional Multiairport System. In the process of flight recovery, in addition to the basic operating resources constraints, it is necessary to control the important risk points of the system, including the risk of terminal area control and scene operation risk. This section describes the 
quantitative risk assessment methods for six risk control points to calculate the risk probability in constraints equations (12)-(17).

2.3.1. The Risk of Terminal Area Control. The risk of terminal area control can be evaluated from the following two aspects.

(1) Airspace Control Workload. The controller's workload has a certain functional relationship with the flow of the flight [22-24]. In addition, it is affected by factors such as the age, the ability to work, the duration of the duty on the day, and the recovery period. We define the formula as

$$
\left\{\begin{array}{l}
\operatorname{Risk}_{s}^{W}=\frac{\beta^{\text {per }} \beta^{\text {wor }} W^{\text {delay }}}{W^{\text {level }}} \\
W^{\text {delay }}=f_{\text {delay }}(N) \\
W^{\text {delay }}=W_{\text {delay }}^{\text {bac }}+W_{\text {delay }}^{\text {fou }}+W_{\text {delay }}^{\text {loop }}+W_{\text {delay }}^{\text {con }}
\end{array}\right.
$$

The following parameters are for airspace controllers and flight recovery period. Let Risk $^{W}$ be risk probability of workload. Let $\beta^{\text {per }}$ be the individual attribute impact factor and $\beta^{\text {wor }}$ be the adjustment factor of the duty period. Note that $W^{\text {delay }}$ is workload generated per unit of time during flight recovery and $W^{\text {level }}$ is maximum workload level per unit time. $f_{\text {delay }}(N)$ is the functional relationship between flight flow $N$ and workload. $W_{\text {delay }}^{\text {bac }}, W_{\text {delay }}^{\text {fou }}, W_{\text {delay, }}^{\text {loop }}$ and $W_{\text {delay }}^{\text {con }}$ are background load, foundational load, cyclic load, and conflict load during recovery, respectively. The calculation of $W^{\text {delay }}$ refers to the controller workload calculation model proposed by Yang [23].

(2) Aircraft Flight Conflict. As shown in Figure 1, four types of flight conflict controllers need to be controlled during the flight (for more information, please refer to Section 5.4.2 of ICAO doc 4444). We define the formula aswhere
$Z_{p} \in\left\{Z_{1}, Z_{2}, \ldots, Z_{p}\right\}$ is the set of route conflict association $Z_{x}(x=1,2, \ldots, P)$. Let Risk $^{C}$ be the risk probability of aircraft conflict frequency. Note that $C_{Z_{x}}$ is the number of collisions that may occur in $Z_{x}$ unit hour, and $C_{Z}^{\text {level }}$ is the maximum of conflicts per unit time allowed in the sector. Let $\alpha_{Z_{x}}$ be the weight of $Z_{x}, Q_{\alpha}\left(Q_{\beta}\right)$ be the hourly traffic on the route $\alpha(\beta)$, and $p_{\mathrm{hc}}\left(p_{\mathrm{vc}}\right)$ be horizontal (vertical) conflict risk probability between routes. The calculation of $C_{Z_{x}}$ refers to the measurement method of conflict risk proposed by Yang [25].

$$
\left\{\begin{array}{l}
\operatorname{Risk}_{s}^{C}=\frac{\beta^{\text {per }} \beta^{\text {wor }} k \sum_{Z_{x}=1}^{x} \alpha_{Z_{x}} C_{Z_{x}},}{C_{Z}^{\text {level }}} \\
C_{Z_{x}}=\min \left(Q_{\alpha}, Q_{\beta}\right) \cdot p_{\mathrm{hc}} \cdot p_{\mathrm{vc}}, \\
Z_{p} \in\left\{Z_{1}, Z_{2}, \ldots, Z_{P}\right\}, p \in\{1,2, \ldots, P\}, \\
\alpha, \beta \in L^{s},
\end{array}\right.
$$

2.3.2. The Risk of Scene Operation. The key risk growth points involved in the scene operation are ground support, apron support, ground control, and taxiing conflict.

(1) Risk Assessment of Ground Support. The general procedure of the near-position service operations is illustrated in Figure 2. The runway capacity and the various service capabilities often do not match. Once a certain operation resource cannot meet the requirements in the recovery plan, it might compress its working time to adapt to other service in the chain, and the risk level will be increased rapidly. The risk of ground service capability can be assessed by evaluating the capabilities of related equipment (equation (20)) and personnel (equation (21)) and calculating the matching degree with support requirements in the recovery plan.

$$
\begin{aligned}
& \left\{\begin{array}{l}
\mathrm{CG}^{v}=\frac{N_{u} n^{v}}{T^{v}}, \\
T^{v}=\sum_{i \in F^{u}, k \in K} \sum_{m \in M, n \in F T} r_{i, k, m, n} E_{k, m, n}\left[t^{v}\right], E_{k, m, n}\left[t^{v}\right]=E_{k, m, n}\left[t_{W}^{v}\right]+E_{k, m, n}\left[t_{H W}^{v}\right]+E_{k, m, n}\left[t_{I}^{v}\right]+E_{k, m, n}\left[t_{D}^{v}\right],
\end{array}\right. \\
& \left\{\begin{array}{l}
\mathrm{CG}^{h}=\frac{N_{u} n^{h}}{T^{h}}, \\
T^{h}=\sum_{i \in F^{u}, k \in K} \sum_{m \in M, n \in \mathrm{FT}^{\prime}} r_{i, k, m, n} E_{k, m, n}\left[t^{h}\right], E_{k, m, n}\left[t^{h}\right]=E_{k, m, n}\left[t_{W}^{h}\right]+E_{k, m, n}\left[t_{H W}^{h}\right]+E_{k, m, n}\left[t_{I}^{h}\right]+E_{k, m, n}\left[t_{D}^{h}\right], \\
\mathrm{Risk}_{u}^{U}=\max \max _{l}\left(\mathrm{CN}_{\mathrm{pl}}^{v}, \mathrm{CN}_{\mathrm{ql}}^{h}\right), \\
\left\{\left(1+\left(k^{\prime} \frac{n^{v}}{n^{v}}-\operatorname{saf}_{u}\right)\right) \frac{F_{u}(t)}{\mathrm{CG}^{v}}, \mathrm{CN}^{h}=\left(1+\left(k^{\prime \prime} \frac{n^{h}}{\overline{n^{h}}}-\operatorname{saf}_{u}\right)\right) \frac{F_{u}(t)}{\mathrm{CG}^{h}}, \quad \forall v \in V, \forall h \in H .\right.
\end{array}\right.
\end{aligned}
$$




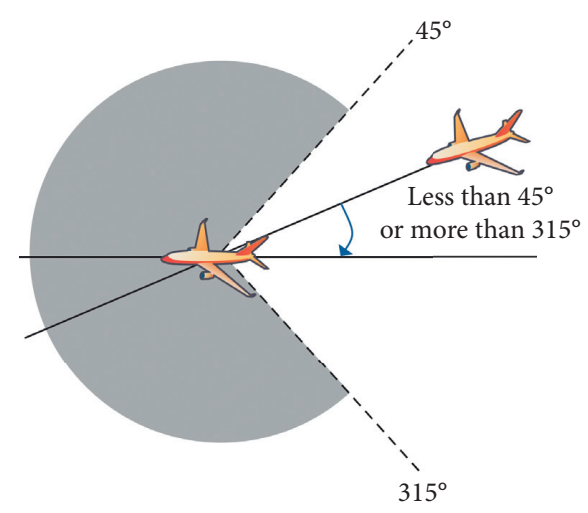

(a)

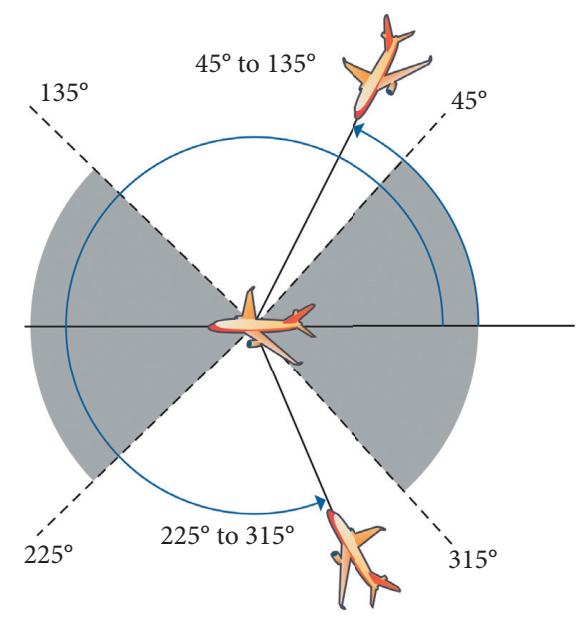

(c)

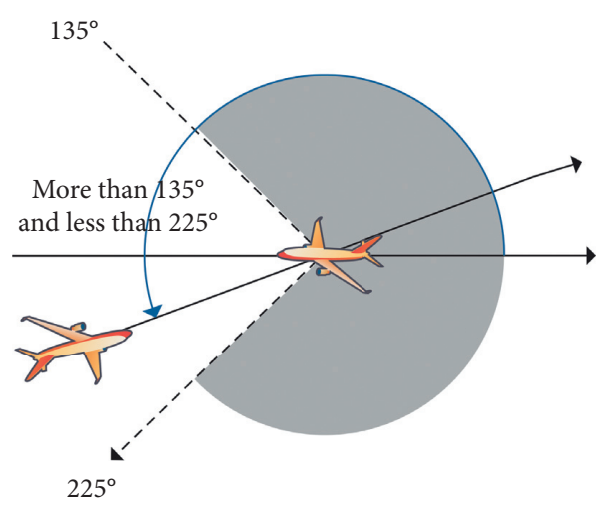

(b)

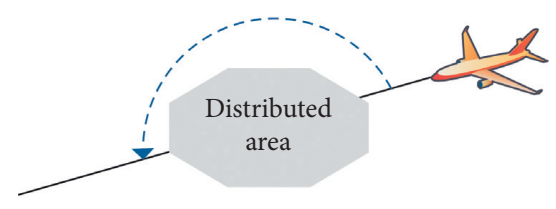

Figure 1: Schematic diagram of flight conflict. (a) Aircraft on same track. (b) Aircraft on reciprocal tracks. (c) Aircraft on crossing tracks. (d) Other flight conflicts.

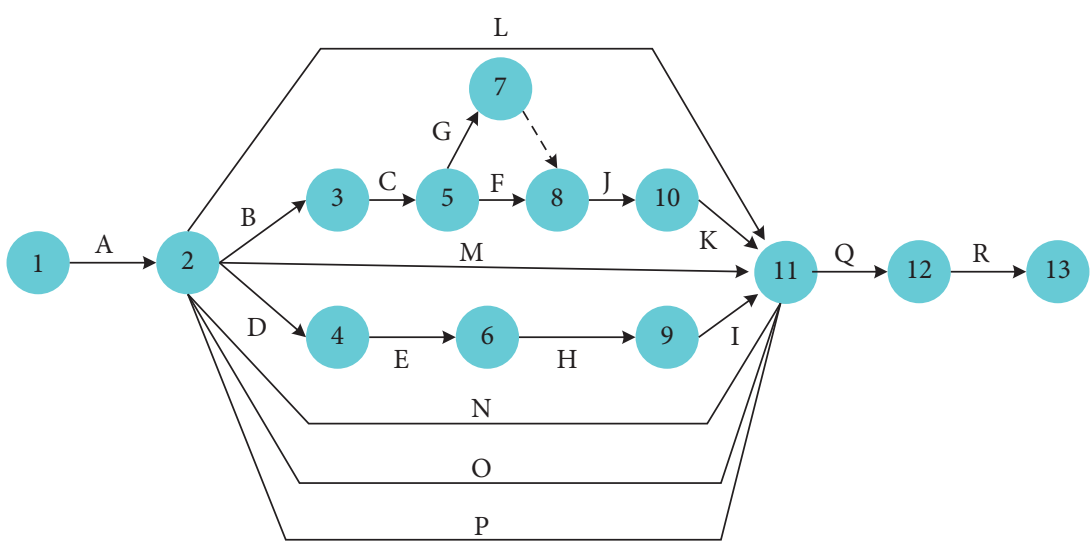

A: block

J: passenger boarding and close the door

B: by bridge

K: remove the bridge

C: open the door, passengers get off the plane

L: refuel

D: open the cargo hatch, unload luggage

M: add clean water

E: unload mail

$\mathrm{N}$ : pumping sewage

F: clear the cabin

O: meal operation

G: clean by garbage truck

P: maintenance inspection

H: load mail

Q: off block

I: load luggage and close the cargo doors

R: pushback

FIGURE 2: Schematic diagram of the near-position service operation process. 
Let $F^{u}$ be the set of flights that need recovery in airport $u, M$ be the set of the types of aircraft, $K$ be the set of attributes of arrival-departure, FT be the set of flight types, and $V(H)$ be the set of ground service equipment (operators) type. Let $\mathrm{CG}^{v}\left(\mathrm{CG}^{h}\right)$ be the maximum service capacity of the equipment (personnel) per unit time, $n^{v}\left(n^{h}\right)$ be the number of equipment (personnel) input per unit time, and $T_{i}^{v}\left(T_{i}^{h}\right)$ be the minimum operating time for this resource serving flight $i . E_{k, m, n}\left[t^{v}\right]\left(E_{k, m, n}\left[t^{h}\right]\right)$ is the minimum expected operating time required for a flight with arrival-departure attribute of $k$, an aircraft model of $m$, and a flight type of $n$ for this equipment (personnel) resource. Note that $N_{u}$ is the total number of flights that need recovery at airport $u$. $E_{k, m, n}\left[t_{W}^{v}\right], E_{k, m, n}\left[t_{H W}^{v}\right], E_{k, m, n}\left[t_{I}^{v}\right]$, and $E_{k, m, n}\left[t_{D}^{v}\right]$ are the minimum time for standard operations, minimum time for auxiliary operations, waiting time required, and general travel time for the operation, respectively. In view of personnel, the definition of $E_{k, m, n}\left[t_{W}^{h}\right], E_{k, m, n}\left[t_{\mathrm{HW}}^{h}\right], E_{k, m, n}\left[t_{I}^{h}\right]$, and $E_{k, m, n}\left[t_{D}^{h}\right]$ is similar to the previous class of parameters. Let Risk be the risk probability of ground service capability, the maximum of $\mathrm{CN}_{\mathrm{pl}}^{v}$ and $\mathrm{CN}_{\mathrm{ql}}^{h}$. $\mathrm{CN}_{\mathrm{pl}}^{v}\left(\mathrm{CN}_{\mathrm{ql}}^{h}\right)$ are the risk probabilities of service capacity for $p$ th ( $q$ th) ground service equipment (operators) on service $l$. Note that $k^{\prime}\left(k^{\prime \prime}\right)$ represents the impact factors of current weather on this service equipment (operators), $\bar{n}^{v}\left(\bar{n}^{h}\right)$ represents average daily input of this equipment (operators), and $\operatorname{saf}_{u}$ is inhibitory factor of risk control. $F_{u}(t)$ is arrival-departure flight traffic at airport $u$ per unit time, and $r_{i, k, m, n}$ is equal to 1 if flight $i$ has an arrival-departure attribute of $k$, a model of $\mathrm{m}$, and a flight type of $n$.

(2) Risk Assessment of Apron Support. We conduct a risk assessment of the ground service capacity in the apron area for two main purposes. One is to avoid the flight recovery plan bringing excessive pressure to a certain apron area, and the other is to reduce conflicts in aircraft operations. As shown in Figure 3, the conflict in the apron area is reflected in the impact of aircraft sliding on the nearby parking lot, lane, and taxiway. The risk assessment of apron service capability is similar to that of ground service.

$$
\operatorname{risk1}^{U_{r}}=\max \left(\mathrm{CN}_{m}^{V_{r}}, \mathrm{CN}_{n}^{H_{r}}\right), \quad \forall p \in V_{r}, \forall q \in H_{r}, \forall r \in L^{r},
$$

$$
\operatorname{risk} 2^{U_{r}}=k^{\prime \prime \prime} \frac{F_{u_{r}}(t)}{\sum_{y=1}^{Q} 1 / E\left[t_{B_{q}}^{r}\right]}, \quad \forall r \in L^{r}, y \in\{1,2, \ldots, Q\}
$$

$\operatorname{Risk}_{u}^{U_{r}}=\max \left(\operatorname{risk} 1^{U_{r}}, \operatorname{risk} 2^{U_{r}}\right), \quad \forall r \in L^{r}$.

Note that $L^{r}$ is the set of aprons, risk $1^{U_{r}}$ is the risk probability of service capability in apron $r$, and $\mathrm{CN}_{p}^{V_{r}}$ and $\mathrm{CN}_{q}^{H_{r}}$ are the risk probabilities of regional service capacity of category $p$ equipment and category $q$ operators in apron $r$, respectively. Let risk $2^{U_{r}}$ be the risk probability of aircraft conflict on the apron, $k^{\prime \prime \prime}$ be the influence factors of current weather, and $F_{U_{r}}(t)$ be the arrival-departure flight flow per unit time in apron $r$ of airport $u$. There are $Q$ groups of associated conflicting gates in an apron, which are represented as $\left\{B_{1}, B_{2}, \ldots, B_{Q}\right\}$. Each associated group $\left(B_{y} y=1,2, \ldots, Q\right)$ contains multiple conflicting gates. $E\left[t_{B q}^{r}\right]$ is the expected time for aircraft sliding to occupy space resources of the association in $B_{q}$ of apron $r$. Risk ${ }_{r}$ is the risk probability of ground service capacity in apron $r$.

(3) The Risk Assessment of Ground Control. It can be calculated by referring to the air traffic control workload; the formula is defined as

$$
\left\{\begin{array}{l}
\operatorname{Risk}_{u}^{W U}=\frac{\beta^{\text {per }} \beta^{\text {Wor }} W^{\text {delay }}}{W^{\text {level }}} \\
W^{\text {delay }}=f_{\text {delay }}(N), \\
W^{\text {delay }}=W_{\text {delay }}^{\text {bac }}+W_{\text {delay }}^{\text {fou }}+W_{\text {delay }}^{\text {loop }}+W_{\text {delay }}^{\text {con }}
\end{array}\right.
$$

Let Risk ${ }^{\mathrm{WU}}$ be the risk of the workload of ground control.

(4) Aircraft Taxiing Conflict. From different parking spaces to different runways, there may be many conflicts in the ground taxiing process, including cross conflicts, rear-end conflicts, and head-to-head conflicts [26], as shown in Figure 4. We define the formula as equation (27)-(29):

$$
\begin{aligned}
& \left\{\begin{array}{c}
\mathrm{CO}=\sum_{d \in L^{0}} \mathrm{NC}_{d}, \\
\mathrm{NC}_{d}=\sum_{d=1}^{n c_{d}-1} \mathrm{es}_{d, j},
\end{array}\right. \\
& \begin{cases}\mathrm{es}_{d, j}=1, & \mathrm{tc}_{d, j+1}-\mathrm{tc}_{d, j}<\mathrm{tc}_{\text {level }}, \mathrm{tc}_{d, j} \neq 0, \mathrm{tc}_{d, j+1 \neq 0}, \\
\mathrm{es}_{d, j}=0, & \text { else. }\end{cases} \\
& \operatorname{Risk}_{u}^{\mathrm{CO}}=\beta^{\mathrm{per}} \beta^{\text {wor }} k^{\prime \prime \prime} \frac{F_{u}^{G}(t)}{\overline{F_{u}^{G}}} \frac{\mathrm{CO}}{\mathrm{CO}^{\text {level }}} \text {. }
\end{aligned}
$$

The aircraft route from a certain apron area to a runway is generally fixed. By transforming the taxiing route into a set $\left(L^{0}\right)$ of multiple conflict nodes, based on the prediction of taxiing time by A-CDM system, the time of each flight passing through the node can be calculated. Furthermore, we can obtain the frequency of taxiing conflict corresponding to different flight recovery schemes. Let $\mathrm{CO}$ be total number of taxiing conflicts predicted by the recovery plan, $\mathrm{NC}_{d}$ be the number of coasting conflicts at node $d$, and tc $c_{j, d}$ be the expiration time of the $j$ th flight through node $d$. Risk ${ }^{\mathrm{CO}}$ is risk probability of aircraft taxiing conflict. $F_{u}^{G}(t)$ represents the number of aircraft taxiing in the scene per unit time, and $\overline{F_{u}^{G}}$ is the average number of aircraft in the scene per unit time. $\mathrm{CO}^{\text {level }}$ is the number of conflict levels acceptable for ground control. es ${ }_{d, j}$ is equal to 1 if the interval time of successive flights passing node $d$ is less than the security interval requirement.

\section{Algorithm Designing}

In the recovery process, due to the uneven demand distribution for each resource, the conflicts among flights occur in 


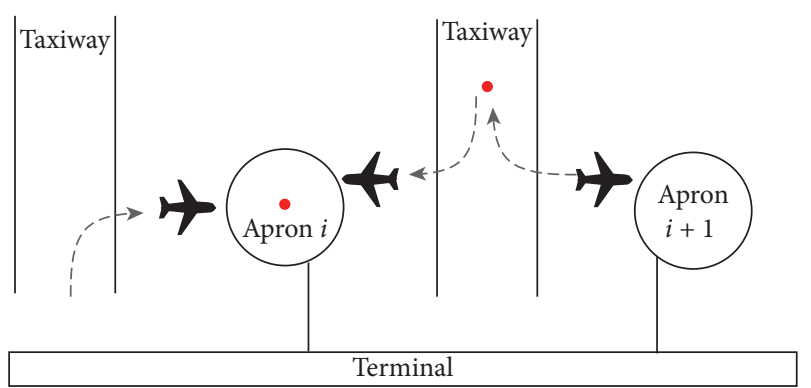

- Point of conflict

$\rightarrow$ The route that slides in or out

Figure 3: Some patterns of aircraft collisions in the aprons.

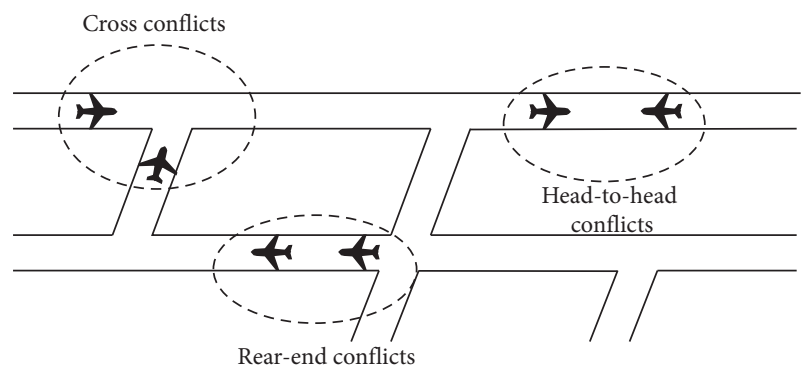

FIgURE 4: The types of coasting conflict.

many aspects. For some tight resources or risky nodes, optimizing the resource allocation will greatly improve the effect of multiobjective function. This paper chooses the multistart algorithm with intelligent neighborhood selection (MSINS) proposed by Molina et al. [27] to solve the model.

The algorithm uses many different neighborhood structures, $N_{m}$, with $1 \leq m \leq m_{\max }$, to characterize the competitive impact of different flights on various resources and improve the initial feasible solution. The main feature of the algorithm is that it can simplify the process of generating random neighborhood solutions in general algorithms, intelligently select the neighborhood search direction, and continuously jump out of the local optimal solution in the loop optimization of multiple objectives. In the solution of multiobjective humanitarian vehicle routing problems, Molina et al. have verified that MSINS has higher advantages than NSGA-II (nondominated sorting genetic algorithm-II) [27].

3.1. Basic Concept of the Algorithm. The MSINS involves the following basic concepts.

3.1.1. Success Indicators. The higher the success indicators of the neighborhood structure, the higher the frequency of use in the objective function. At the beginning of each local loop, initialize the success indicators of $N_{m}: \mathrm{OP}_{m}=\operatorname{min~OP}+\mathrm{ES}_{m}$. In the current search, $\mathrm{OP}_{m}=\mathrm{LOP}_{m} / \mathrm{Cd}_{m}$.

3.1.2. Evaluation Score. $\mathrm{ES}_{m}$ represents the evaluation score of $N_{m}$ in the global improvement of optimal value, $\mathrm{ES}_{m}=\left(\mathrm{GCd}_{m} / \mathrm{TCd}\right)+\left(\mathrm{GOP}_{m} / \mathrm{TOP}\right)$. It determines the initial order to call the neighborhood structures. $\mathrm{Cd}_{m}$ and $\mathrm{GCd}_{m}$ represent the number of times the $N_{m}$ have been called in current local search and in global search, respectively. $\mathrm{LOP}_{m}$ and $\mathrm{GOP}_{m}$ represent the number of times the current solution and global optimum are improved using $N_{m}$ in current local and global search, respectively. Note that TCd is the total number of calls of all $N_{m}$ until the moment. TOP is the total number of optimizations improved.

3.2. The Structure of the Algorithm. In dealing with the multiobjective optimization, the algorithm searches each single-objective optimization one by one based on the proximate optimality principle (POP) [28]. In the first single-objective optimization $f_{1}$, the first local search starts from an arbitrary point and attempts to find the optimal solution. Let $x_{1}$ be the last point visited at the end of the search. In the second single-objective optimization $f_{2}$, a local search is applied again to find the best solution by regarding $x_{1}$ as the initial solution. After all the singleobjective optimizations are repeated, the compromise functions with random weights are used as the new objective functions to perform global optimization for achieving the final approximation of the effective set.

The solution framework based on MSINS is as follows:

Step 1: read and input data information.

Step 2: generate the initial flight scheduling and the initial solution. According to the initial flight schedule, assign the take-off and landing time to the flight in turn and generate the initial solution. The initial solution is the current solution, which includes the flight initial schedule $x_{0}$, the target runway time et ${ }_{0}$, the target runway allocation $\mathrm{pd}_{0}$, and other variable information.

Step 3: 5(a))firstly, three functions are constructed, which are the single objective function of delay time (equation (30)), the compound function with fixed weights (equation (31)), and the compromise function with random weights (equation (32)). According to the flow of the global loop (Figure 5(a)), the three functions are substituted in turn into the local loop (Figure 5(b)) based on intelligent neighborhood selection to calculate the solutions.

$\mathrm{OBJ}_{1}=\sum_{i \in F} \mathrm{DT}_{i}$

$$
\begin{aligned}
& \mathrm{OBJ}_{2}=a \sum_{i \in F} \mathrm{DT}_{i}+b \sum_{t \in T} \operatorname{Risk}(t), \quad a, b \in C \\
& \mathrm{OBJ}_{3}=\mu_{1} \sum_{i \in F} \mathrm{DT}_{i}+\mu_{2} \sum_{t \in T} \operatorname{Risk}(t), \quad \mu_{1}=\operatorname{rand}() ; \mu_{2}=1-\mu_{1} .
\end{aligned}
$$

In the process of intelligent neighborhood selection, first, enter the current solution and the objective function to determine the initial values of parameters in 
current search. Second, select neighborhood structure with the best success indicators $N_{B_{s}}$ to generate a new solution, according to whether the new solution optimizes the current objective function to update all variable values, and then reselect $N_{B_{s}}$. Finally, the algorithm repeats the process of generating the new solution by using the newly selected $N_{B_{c}}$, until $\mathrm{OP}_{m}$ of all $N_{m}$ are less than the acceptable level min OP. The initialization of $\mathrm{OP}_{m}$ ensures that each neighborhood structure is used at least once in the optimization process.

Step 4: calculate the number of effective solutions at the end of the global loop (CAfter). Whether the algorithm continues to iterate depends on whether CAfter is equal to CBefore (Figure 5(a)). CBefore represents the number of effective solutions obtained at the end of the last global loop. If it is the same, the algorithm terminates (based on the idea of Pareto optimal solution); otherwise, return to reexecute Step 3.

Subalgorithm 3 presents the pseudocode summarizing the main steps of the allocation about flight take-off and landing time (Algorithm 1).

3.3. The Neighborhood Structures. In the regional multiairport system, there is a competitive relationship between flights and space-time resources in the terminal area, and different risk units have a certain impact on the system risk probability. Therefore, the following neighborhood structure is designed to generate neighborhood solution in this paper.

$N_{1}$ : select two flights randomly and exchange their flight sequences.

$\mathrm{N}_{2}$ : select two flights randomly and determine whether the flights use the same airport; if so, re-randomly select two flights to judge again; if not, exchange their flight sequences.

$N_{3}$ : select two flights randomly and determine whether the flights use the same runway; if so, re-randomly select two flights to judge again; if not, exchange their flight sequences.

$N_{4}$ : select two flights randomly and determine whether the flights use the same apron; if so, re-randomly select two flights to judge again; if not, exchange their flight sequences.

$N_{5}$ : select two flights randomly and determine whether the flights pass through the same sector; if so, rerandomly select two flights to judge again; if not, exchange their flight sequences.

$N_{6}$ : select two flights randomly and determine whether the flights pass through the same arrivaldeparture locations; if so, re-randomly select two flights to judge again; if not, exchange their flight sequences.

$N_{7}$ : select a flight randomly and determine whether the runway can be replaced; if possible, change it and generate neighborhood solution; if not, re-randomly select flights and judge again.

This paper sets $\min \mathrm{OP}$ to 0.75 and sets the minimum iteration number to 3000 .

\section{Case Study and Result Analysis}

4.1. Simulation Scenarios. To validate the performance of the proposed regional multiairport abnormal flight recovery method based on risk control, the data of a typical regional multiairport system in China were selected for experimental verification. The specific scenarios are set as follows.

The terminal airspace consists of 6 arrival locations and 12 departure locations, of which 3 locations can control different heights for arrival and departure. The system is divided into four sectors in the experiment (see Figure 6).

The runway operation mode of the two airports on the day is to run northward (see Figure 7). Airport A has three runways: runway 1 is used for departure, runway 2 is used for approach, and runway 3 is used for both approach and departure. $1 / 3$ of runways depart by independent parallel, and $2 / 3$ of runways approach by independent parallel. Airport B has two runways: runway 4 for departure and runway 5 for approach.

According to the gate distribution and runway configuration of $\mathrm{A}$ and $\mathrm{B}$ airports, the apron operation area of airport $A$ and airport $B$ is divided into six areas (AL1 AL6) and five areas (BL1 BL5), respectively. The positions of divided areas and taxiway system for the two airports are shown in Figures 8 and 9.

In the experiment, we select the arrival-departure flight data of the system during 15:00-16:59 for simulation verification. Due to bad weather, during 13:00-14:59, the air traffic control flowed some of the arrival-departure points, and the two airports had many flights delayed to the subsequent time. During the period, a total of 215 flights needed recovery, of which 55 were predicted to approach and 63 to depart at airport $A$ and 39 were predicted to approach and 58 to depart at airport B. There were 15 and 17 delayed flights during the previous period at airports $\mathrm{A}$ and $\mathrm{B}$, respectively.

Based on the specific information about the delayed flights (see Table 1 in the Supplementary Material), we can get the number of flights requiring each arrival-departure location (Table 1) and the number of flights requiring the aprons for ground service (Table 2). Let AF and DF be the arrival and departure locations, respectively.

The arrival and departure requirements for various sectors in the terminal area of the system are shown in Table 3.

According to Section 5.8 "Time-based wake turbulence longitudinal separation minima" in the ICAO doc 4444, combined with the relevant literature [29], the wake intervals between different types of approach aircraft are shown in Table 4. For departing flights, the release interval is considered in the actual control work, that is, $120 \mathrm{~s}$ in the same direction and $180 \mathrm{~s}$ in different directions. 


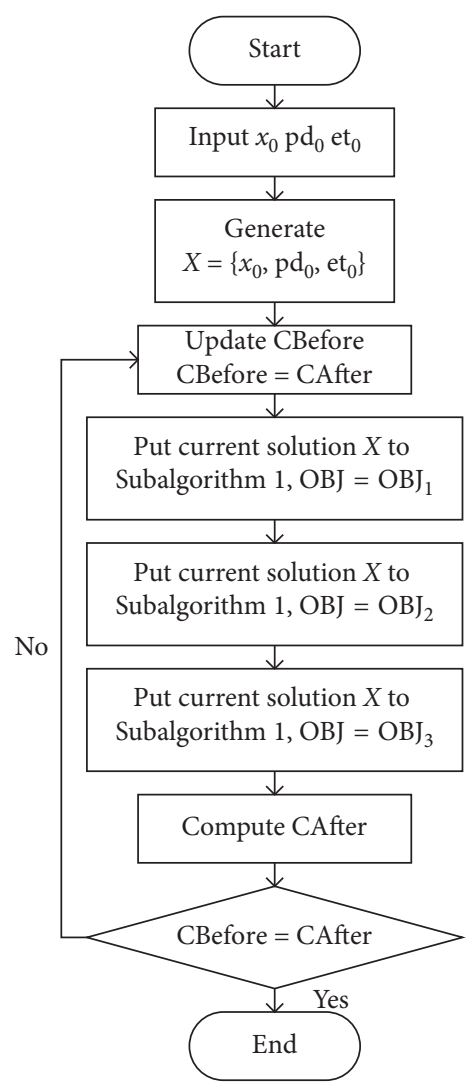

(a)

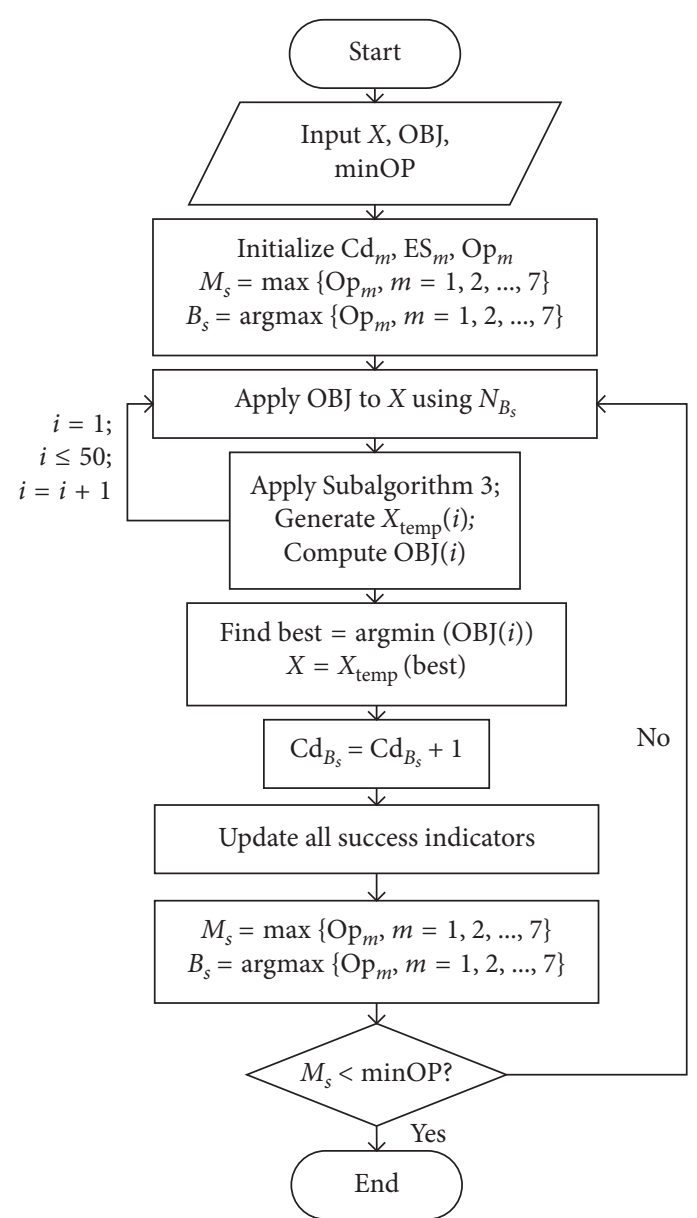

(b)

FIGURE 5: Application framework of MNINS. (a) Subalgorithm 2: the framework of global loop. (b) Subalgorithm 1: the framework of local loop.

(1) Input $x, \mathrm{pd}$, All constraint indicator

(2) for $\left(m=1 ; m<=N_{F} ; m++\right)$

(3) $\quad i=x(m)$, Initialize: et $(i)=$ st $(i)$

(4) if $\lambda_{i, j} \eta_{i, j} \gamma_{i, j}\left(\mathrm{ET}_{i}+\sigma_{i, j}\right) \leq \mathrm{ET}_{j}$ is False, Then Update: et $(i)$

(5) if $\lambda_{i, j} \theta_{i, j, m, n}\left(\mathrm{ET}_{i}+v_{i, j, m, n}\right) \leq \mathrm{ET}_{j}$ is False, Then Update: et $(i)$

(6) if $\lambda_{i, j} \gamma_{i, j}\left(\mathrm{ET}_{i}+l_{i}\right) \leq \mathrm{ET}_{j}$ is False, Then Update: et $(i)$

(7) if $\omega_{i, j} \rho_{i, j}\left(\mathrm{LPT}_{i}+\delta_{i, j}\right) \leq \mathrm{LPT}_{j}$ is False, Then Update: et $(i)$

(8) if $\left(\mathrm{FA}_{u}(t), \mathrm{FD}_{u}(t)\right) \in \mathrm{CR}_{u}(t)$ or $\mathrm{FA}_{u}^{i}(t)-\mathrm{FD}_{u}^{i}(t) \leq \mathrm{CP}_{u}^{i}(t)$ is False, Then Update:et $(i)$

(9) if $\operatorname{Risk}_{u}^{U}(t) \leq \operatorname{Risk}_{\text {level }}^{U}$ or Risk ${ }_{u}^{\mathrm{WU}}(t) \leq \operatorname{Risk}_{\text {level }}^{\mathrm{WU}}$ is False, Then Update:et $(i)$

(10) if $\operatorname{Risk}_{u}^{U_{r}}(t) \leq \operatorname{Risk}_{\text {level }}^{U_{r}}$ is False, Then Update:et $(i)$

(11) if $\mathrm{FS}_{s}(t) \leq \mathrm{CS}_{s}(t)$ or Risk ${ }_{s}^{W}(t) \leq \operatorname{Risk}_{\text {level }}^{W}$ is False, Then Update:et (i)

(12) Update: et $(i)$, the flow of all resources

(13) end for

(14) Compute the number of flight conflict and taxi conflict

(15) if $\operatorname{Risk}_{s}^{C}(t) \leq \operatorname{Risk}_{\text {level }}^{C}$ or $\operatorname{Risk}_{u}^{C O}(t) \leq \operatorname{Risk}_{\text {level }}^{\mathrm{CO}}$ or $\mathrm{LT}_{i} \leq \mathrm{ET}_{i} \leq \mathrm{UT}_{i}$ is False,

(16) Then return Subalgorithm 2, using $N_{B_{s}}$ again

Algorithm 1: Subalgorithm 3: allocation about flight take-off and landing time.

The safety interval of arrival-departure points is set at 10 nautical miles. According to the type of aircraft, the approach speeds of heavy, large, and small aircraft are $160 \mathrm{kN}$, $145 \mathrm{kN}$, and $120 \mathrm{kN}$, respectively. The taxiing speed of the aircraft on the ground is unified as $10 \mathrm{kN}$. According to the research on the literature related to the airport runway capacity [30], the runway occupancy time of all kinds of aircraft is set as shown in Table 5 . 


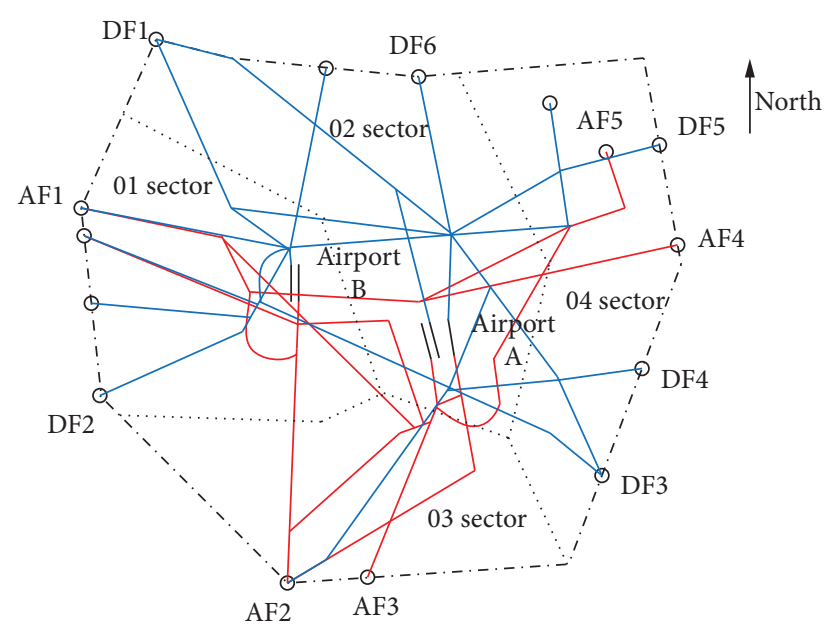

-.. The boundary of terminal area Boundary of sector

- Arrival-departure locations

- Approach route

- Departure route

- Runway

Figure 6: Airspace structure of terminal area in a regional multiairport system.

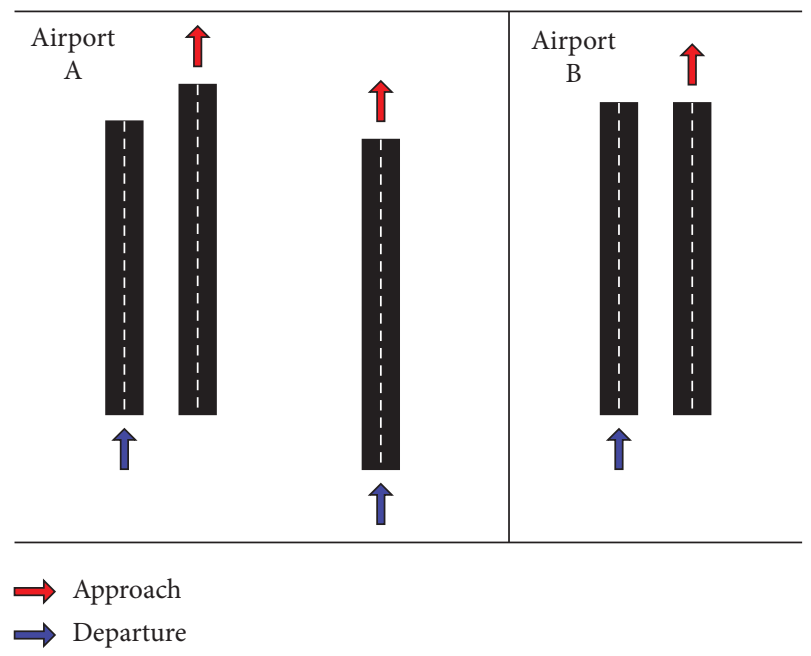

FIgURe 7: Schematic diagram of the runway modes of the two airports $\mathrm{A}$ and $\mathrm{B}$.

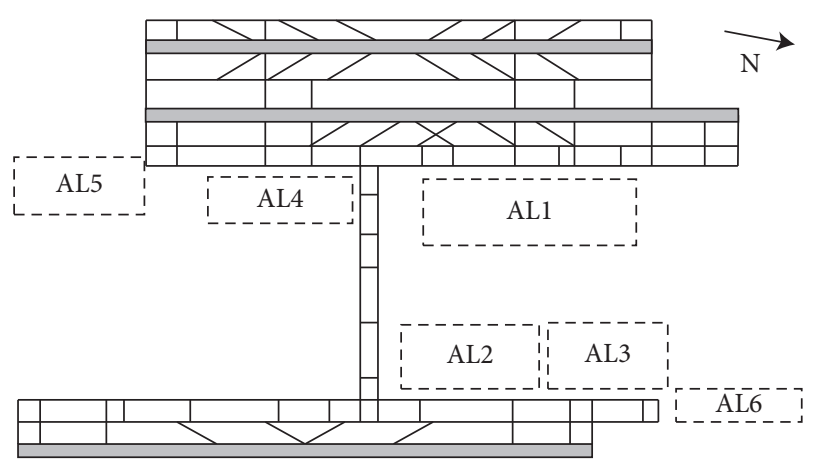

Figure 8: Apron and taxiway system in airport A.

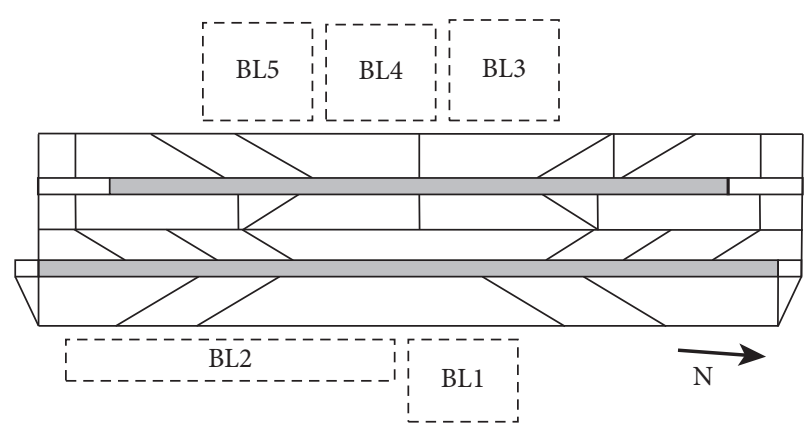

Figure 9: Apron and taxiway system in airport B.

With reference to the related research [23], set the runway capacity per hour of airport A to meet the capacity curve $\left(0 \leq u_{t} \leq 30,0 \leq v_{t} \leq 34, u_{t}+v_{t} \leq 60\right)$. Set the runway capacity per hour of airport $\mathrm{A}$ to meet the capacity curve $\left(0 \leq u_{t} \leq 26,0 \leq v_{t} \leq 26, u_{t}+v_{t} \leq 49\right)$. Let $u_{t}$ and $v_{t}$ be the arrival and departure flow, respectively. The sector capacity is 35 per hour.

\subsection{Flight Data Preprocessing}

S1.1: read data from the regional multiairport system and combine the correlation capacity constraints with the corresponding resource information for digital processing.

S1.2: input flight information and calculate formulas (18) to (21). We can get the data of standards; determine the lower and upper limit $\left(\mathrm{LT}_{i} \& \mathrm{UT}_{i}\right)$ of arrival-departure flight time window.

S1.3: read the parameters involved in risk assessment model. Based on the regional multiairport system parameters identified in Section 4.1, we determine the thresholds for some parameters (such as the load limit of the controller and the upper limit of the service capacity of each apron), as shown in Tables 6 and 7. Further, the threshold of each risk point is calculated according to the risk quantitative formula (equations (18)-(29)), where the conflict frequency limit of each sector is shown in Table 8.

S1.4: according to the estimated take-off and landing time of flights, the initial flight schedule is generated based on FCFS (first come first served).

4.3. Result Analysis. The flight recovery model based on risk control with MSINS was programmed in MatlabR2018b. In this section, we conduct several groups of experiments according to the example scenario and analyze the resulting data in multiple dimensions. This section analyzes the result data from the effectiveness of the algorithm, the risk points that need to be controlled most, and the flight recovery effects of RCM, TRM, and FCFS. The importance of risk control in the recovery of abnormal flights in the regional multiairport system is discussed. 
TABle 1: Flight demand for arrival and departure points.

\begin{tabular}{lccccccccccc}
\hline \multirow{2}{*}{ Airport } & \multicolumn{4}{c}{ Number of flights required for arrival locations } & \multicolumn{4}{c}{ Number of flights required for departure locations } \\
& AF1 & AF2 & AF3 & AF4 & AF5 & DF1 & DF2 & DF3 & DF4 & DF5 & DF6 \\
\hline A & 18 & 13 & 4 & 9 & 11 & 19 & 13 & 4 & 4 & 11 \\
B & 19 & 19 & 0 & 0 & 1 & 27 & 5 & 14 & 12 & 0 \\
\hline
\end{tabular}

TABLE 2: Demand for ground support services for flights in the apron area.

\begin{tabular}{lc}
\hline Apron area & Number of flights requiring this resource \\
\hline AL1 & 23 \\
AL2 & 23 \\
AL3 & 25 \\
AL4 & 24 \\
AL5 & 9 \\
AL6 & 14 \\
Total & 118 \\
BL1 & 12 \\
BL2 & 8 \\
BL3 & 28 \\
BL4 & 22 \\
BL5 & 27 \\
- & - \\
Total & 97 \\
\hline
\end{tabular}

TABle 3: The arrival and departure demand for each sector.

\begin{tabular}{lc}
\hline Sector & Number of flights requiring this resource \\
\hline 01 & 55 \\
02 & 58 \\
03 & 36 \\
04 & 66 \\
\hline
\end{tabular}

TABLE 4: Requirements for wake-vortex separation interval.

\begin{tabular}{ccccc}
\hline & & 3 & Trailing \\
& & Heavy & Large & Small \\
\hline \multirow{3}{*}{ Leading } & Heavy & $99 \mathrm{~s}$ & $120 \mathrm{~s}$ & $180 \mathrm{~s}$ \\
& Large & $74 \mathrm{~s}$ & $107 \mathrm{~s}$ & $180 \mathrm{~s}$ \\
& Small & $74 \mathrm{~s}$ & $80 \mathrm{~s}$ & $98 \mathrm{~s}$ \\
\hline
\end{tabular}

TABle 5: Time of aircraft occupation of runway.

\begin{tabular}{lcc}
\hline & Arrival (s) & Departure (s) \\
\hline Heavy & 70 & 55 \\
Large & 60 & 55 \\
Small & 50 & 55 \\
\hline
\end{tabular}

4.3.1. Effectiveness of the Algorithm. Solving the model based on MNINS and related data, we can get the iterative process of the effective solution based on RCM (risk control model) and the TRM (traditional recovery model) (Figure 10). Because of the correlation between the optimization objectives, the algorithm only sets up a single-objective optimization process for the delay time, that is, it takes the delay time as the main optimization direction.
For the optimization process of the delay time, it has gradually converged after about 600 iterations in the RCM, and it has gradually converged after about 1000 iterations in TRM. The trend of the current effective solution set is no longer obvious, which verifies the effectiveness of the algorithm. Due to the limitation of the minimum of iterations, the algorithm does not stop. In the following 1000 iterations, the delay time is improved and fluctuates in a small range. The ability of the multiobjective alternating optimization mechanism to jump out of local optimal solution is further verified. The risk of each period is calculated according to formula (3), which is the weighted sum of 6 risk key points. Risk probability of the system $\left(\sum_{t \in T} \operatorname{Risk}(t)\right)$ is the sum of risks in each period. The delay time of each flight is calculated according to formula (2), and the total delay time of the system $\left(\sum_{i \in F} \mathrm{DT}_{i}\right)$ is the sum of all flights. In the view of risk probability, the range of risk probability is $8.5-10$ due to the risk control on key points for RCM. While TRM only includes basic capacity constraints and interval constraints, the risk probability is $8.7-11$. It can be seen that some feasible solutions generated by the TRM cannot meet the risk control constraints, that is, the implementation of the solution has a certain security risk.

4.3.2. The Analysis of Six Key Risk Points. This section uses the TRM and MNINS to simulate different scenarios to explore the risk control points that need to be controlled most. Ten sets of experiments were carried out on each of the five scenarios (the original scene; airport A has more or less flight delays than airport B; the total delay of approach flights is greater or smaller than that of departure flights). Figure 11 shows a comparison of risk points exceeding threshold (1.0) in 50 groups of experiments in the TRM case, where flight conflicts and apron support are the risk points that need to be controlled most.

In the TRM, capacity constraints and interval constraints can control the flight flow of a single airport to a certain extent. The constraints on runway capacity and wake interval can limit the number of flights in a single airport, and the risks of taxiing conflict, ground control, and ground service can be controlled at a low level. Constraints on sector capacity can indirectly ensure that the risk of air traffic control personnel load is below the threshold.

Nevertheless, TRM is unable to effectively control the risk of apron support and flight conflicts. (1) In the context of flight delays, staff need to improve the operational efficiency of the airport to alleviate the contradiction between limited resources and flight requirements, which greatly increases the risk of system operation. Due to the failure to consider the ground risk, the apron support becomes a higher risk link, and it is prone to friction or collision events. 
TABLE 6: Constraints of sector risk control.

\begin{tabular}{lcr}
\hline Sector & Maximum number of flights for controllers (h) & Conflict frequency limit (h) \\
\hline 01 & 34 & 0.000824 \\
02 & 33 & 0.000863 \\
03 & 35 & 0.000907 \\
04 & 34 & 0.000954 \\
\hline
\end{tabular}

TABLE 7: Constraints of airport risk control.

Airport Upper limit of flights for controllers (h) Upper limit on the number of ground service (h) Acceptable number of conflicts (h)

\begin{tabular}{llll}
\hline $\mathrm{A}$ & 60 & 62 & 20 \\
$\mathrm{~B}$ & 50 & 48 & 10 \\
\hline
\end{tabular}

TABLE 8: Constraints of risk control in apron area.

\begin{tabular}{lccc}
\hline Apron area & Upper limit of flights served by the apron (h) & Apron area & Upper limit of flights served by the apron (h) \\
\hline AL1 & 13 & BL1 & 6 \\
AL2 & 13 & BL2 & 6 \\
AL3 & 13 & BL3 & 15 \\
AL4 & 13 & BL4 & 15 \\
AL5 & 7 & BL5 & 15 \\
AL6 & 7 & - & - \\
\hline
\end{tabular}

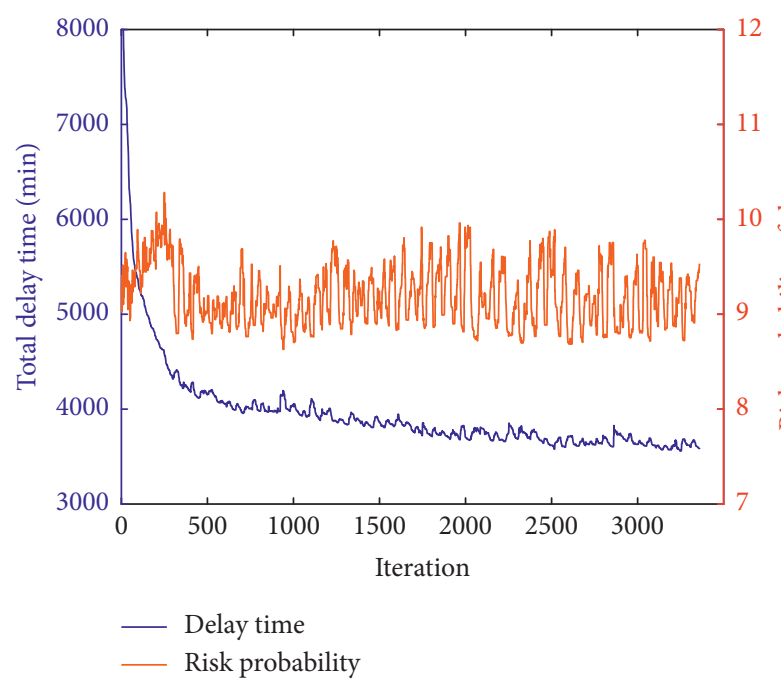

(a)

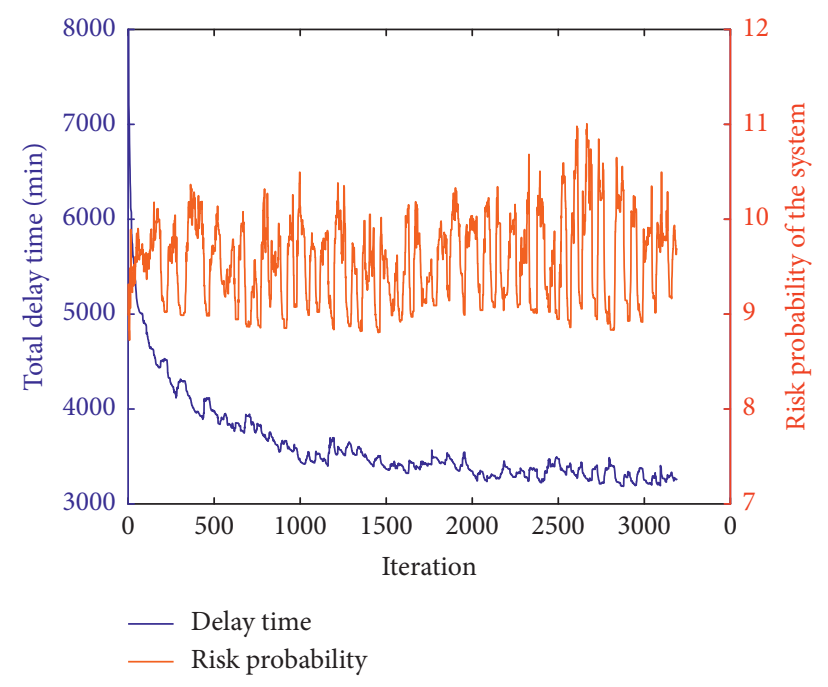

(b)

FIgURE 10: Iterative process based on (a) RCM and (b) TRM.

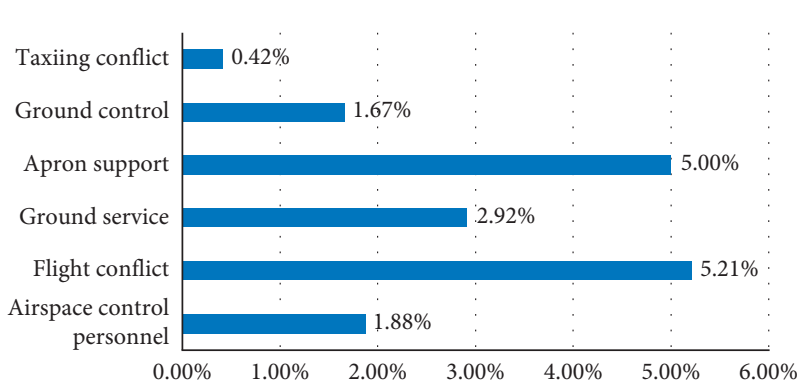

FIGURE 11: Comparison of six risk control points exceeding threshold.
(2) In the RMAS, the airspace structure is complex and there are many arrival-departure conflict points. Flights in the terminal area could experience the cross convergence of different routes in a short time. Once the bad weather occurs, it is very easy to cause the shortage of shared route resources of each airport. The interval constraint of the TRM can only restrict the flights on the runway/the same route, but cannot restrict the flight conflict during the approach and departure. Flight conflict has also become a major hidden danger.

4.3.3. The Comparison with the FCFS. In the actual operation process, the flight scheduling is mainly based on FCFS (first 
come first served), which generally includes two flight scheduling methods: based on arrival-departure location and based on runway. This section compress risk control methods and traditional recovery methods with FCFS strategies to explore the differences in delay time and risk probability.

Figure 12 shows the distribution of feasible solutions and efficient solutions generated by the two methods. In the effective solutions, the two solutions of the shortest delay time and the lowest risk probability are found and compared with the optimal solutions generated by FCFS, respectively. The two methods are greatly optimized for the initial solution of flight delay time (Table 9). In the optimization scheme with the shortest delay time, the risk probability increases to a certain extent, but the delay time is shortened by nearly $55 \%$. In the optimization scheme with the lowest risk probability, the delay time is greatly optimized (about 50\%) and the risk probability is reduced. On the whole, TRM and RCM are better than FCFS strategy.

4.3.4. Comparative Analysis of RCM and TRM. According to the effective solutions obtained in Section 4.3.3 (Figure 12), the effective solutions obtained by the two methods are analyzed from two dimensions: delay time and risk probability. In effective solutions with lower delay time, the delay time of the effective solution obtained by RCM is slightly higher, but it can ensure that the system is in a lower risk probability. In the comprehensive solution and the effective solution with the optimal risk probability, the performance of the RCM is better than that of TRM in terms of delay time and risk probability (see Figure 13). From the overall distribution of the effective solutions, the RCM has a better disposal effect of abnormal flights.

In order to further explore and compare the effective solution with the shortest delay time and the lowest risk probability between the two methods, 10 groups of experiments were conducted on the two models by using MSINS. Table 10 reports the average value of results by using the delay time and the risk probability as the optimal conditions for the effective solution set. When the delay time is taken as the optimal solution condition (select the effective solution with the shortest delay time), the RCM can reduce the operation risk of the system by $3.14 \%$, but the flight delay time is a little longer. When the risk probability is taken as the optimal decision condition, the RCM has advantages in two aspects: it can reduce the risk of system operation and the delay time of flights at the same time. In the group of experiments that had the most obvious effect of improvement, the system risk probability was reduced by $3.15 \%$, and the overall delay time was reduced by $12.62 \%$.

On the other hand, the delay time of each flight can be compared from a microperspective. Considering the flight recovery demand in the abnormal flight situation, based on the effective solution with the lowest risk probability, the mean of each flight delay time of the two models in the 10 sets of experiments is obtained and compared (Table 11).
The following data conclusions can be obtained (see Figure 14). Among the 215 flights, the average flight delay time of the traditional recovery model is 21.83 minutes, while that of the RCM is only 16.98 minutes. TRM has 157 flights with longer delays than RCM, accounting for $73.02 \%$, and $3.7 \%$ of the gap is greater than 20 minutes. Furthermore, the number of flights with delay time less than 5 minutes obtained by RCM is 56, which is more than 3 times that of the traditional model, which can save considerable recovery cost for airlines. The number of flights with delay time less than 15 minutes using RCM (we usually take 15 minutes as acceptable delay value) is $60 \%$, while that of the TRM is only $50.23 \%$. Therefore, the RCM has obvious advantages in delay time optimization on the basis of ensuring the security of the system.

Figures 15 to 18 are comparative diagrams of the mean risk probabilities of the key risk nodes in the optimal solution generated by the two methods based on the optimal risk probability. The traditional recovery method airspace control risk probability exceeds the acceptable level in sector 04 in 16:00-16:59, and the excessive fatigue of controllers threatens operational safety (Figure 15). Figure 16 represents a comparison about the risk probabilities of flight conflict. The risk probability of flight conflict of TRM in most areas is significantly higher than that of risk control methods. In addition, the risk probability in sectors 1 and 2 exceeds an acceptable level during the period of 15:00-15:59. Moreover, the risk probability of sector 1 exceeds a large range in both periods. At this time, the probability of flight conflict in the sector increases, and controllers may have problems such as untimely conflict resolution. There are major security risks in the airspace of the terminal area.

Figure 17 shows the comparison of ground support (A3 and $\mathrm{B}-3)$, ground control (A-4 and $\mathrm{B}-4)$, and taxiing conflict risk probabilities (A-5 and B-5) between the two airports after optimization. In 16:00-16:59, the risk probability of the TRM is higher than that of the RCM. And the risk probability of the traditional model on the ground support exceeds the threshold. The risk probabilities of the TRM in the AL6 and BL5 apron areas are all higher than acceptable level, while the risk probabilities of the schemes obtained by the RCM are also high (see Figure 18). It shows that at this time, the demand for flight service in the apron area is great, and the investment of resources cannot meet the demand of the traditional scheme. The risk control method can effectively control the risk in the apron within its guarantee capacity.

By comparing the risk probabilities of the two methods at the aprons, it can be found that 1)the optimization scheme generated by the RCM effectively controls the risk probability within the acceptable level.2) The value of risk probabilities is lower than that of the TRM in most cases. In addition, in some cases, the risk of the optimization scheme obtained by the RCM is slightly higher than that of the TRM, which is the result of the resource optimization of the RCM. For example, the TRM exceeds the risk threshold in AL6 and BL3 at 16:00-16:59, and the RCM allocates the flight flow of 


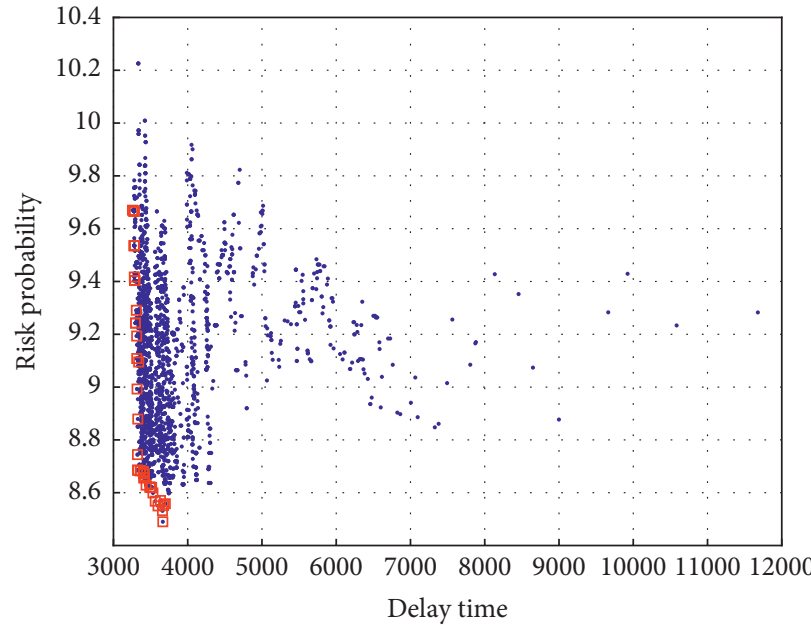

- Feasible solution

- Effective solution

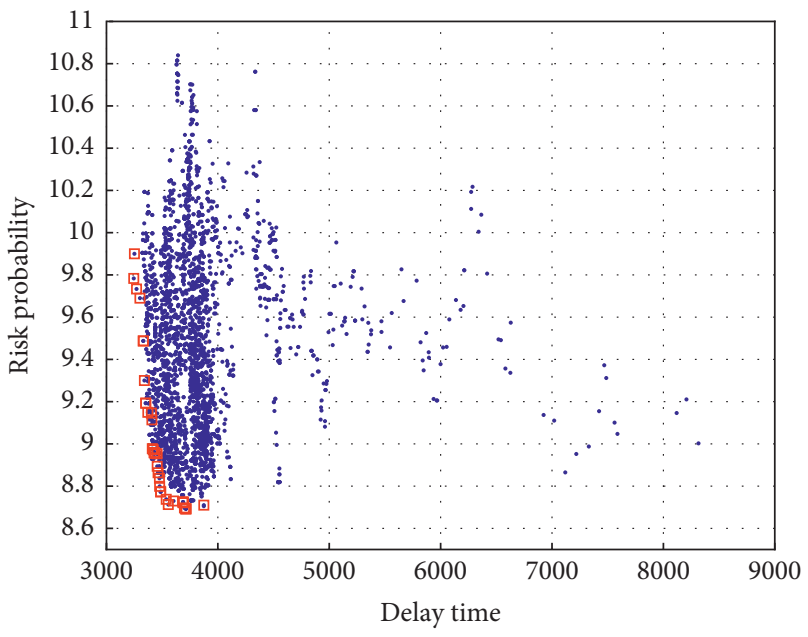

- Feasible solution

- Effective solution

(a)

(b)

Figure 12: Feasible solutions and efficient solutions distribution of (a) RCM and (b) TRM.

TABLE 9: Comparison of multiobjective optimization results.

\begin{tabular}{|c|c|c|c|c|c|c|}
\hline \multirow{2}{*}{ Optimization objective } & \multicolumn{3}{|c|}{ Risk control method (RCM) } & \multicolumn{3}{|c|}{ Traditional recovery method (TRM) } \\
\hline & FCFS & Optimal delay time & Optimal risk probability & FCFS & Optimal delay time & Optimal risk probability \\
\hline Delay time gap & 7386 & $\begin{array}{c}3256 \\
-55.79 \%\end{array}$ & $\begin{array}{c}3665 \\
-50.37 \%\end{array}$ & 7299 & $\begin{array}{c}3251 \\
-55.46 \%\end{array}$ & $\begin{array}{c}3874 \\
-46.92 \%\end{array}$ \\
\hline Risk probability gap & 8.91 & $\begin{array}{c}9.67 \\
8.53 \%\end{array}$ & $\begin{array}{c}8.49 \\
-4.71 \%\end{array}$ & 9.16 & $\begin{array}{c}9.90 \\
8.08 \%\end{array}$ & $\begin{array}{c}8.71 \\
-4.91 \%\end{array}$ \\
\hline
\end{tabular}

Note. "Gap" refers to the gap between the optimal efficient solution obtained by RCM or TRM and the scheme obtained by FCFS. For example, the "delay time gap" between the effective solution with the shortest delay obtained by RCM and the FCFS scheme is calculated as follows: $(3256-7386) / 7386 * 100 \%=-55.79 \%$.

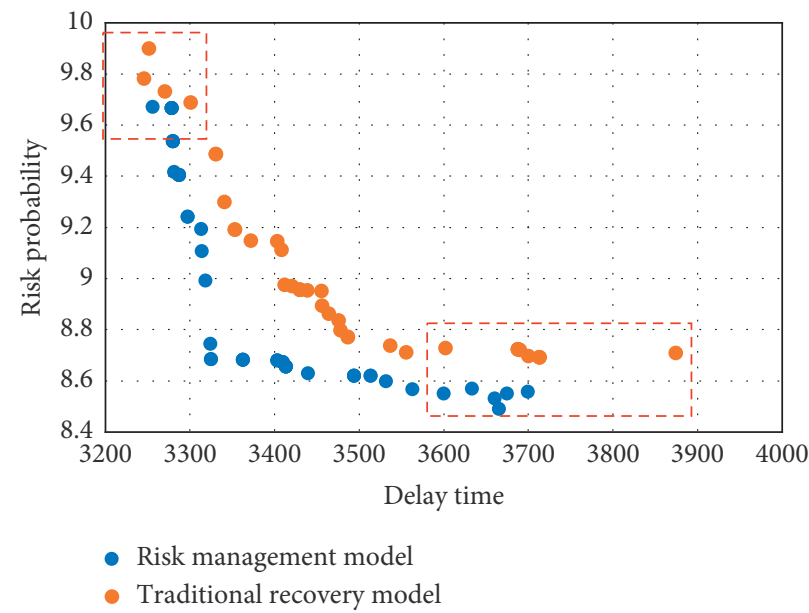

FIgURE 13: Comparison diagram of efficient solutions between RCM and TRM.

the two aprons to another airport at the same period or next time slot. Therefore, the risk produced by RCM is higher for AL6 and BL5 at 15:00-15:59.
Compared with the traditional recovery method, the risk control method can effectively avoid the uneven demand for terminal resources, and it has a stronger applicability to the 
TABLE 10: Comparison of efficient solutions between RCM and TRM.

\begin{tabular}{lcccc}
\hline \multirow{2}{*}{ Optimization objective } & \multicolumn{2}{c}{ Risk control method (RCM) } & \multicolumn{2}{c}{ Traditional recovery method (TRM) } \\
& Optimal delay time & Optimal risk probability & Optimal delay time & Optimal risk probability \\
\hline Delay time & 3350.0 & $\mathbf{3 7 4 2 . 5}$ & 3313.2 & \multirow{2}{*}{$\mathbf{3 8 9 5 . 8}$} \\
Gap & $+1.11 \%$ & $\mathbf{- 3 . 9 4 \%}$ & \multirow{2}{*}{$\mathbf{8 . 4 6}$} & $\mathbf{8 . 6 6}$ \\
\hline Risk probability & 9.56 & $-\mathbf{2 . 3 4 \%}$ & \\
Gap & $-3.14 \%$ & &
\end{tabular}

Note. "Gap" refers to the gap between the optimal efficient solutions obtained by RCM and TRM. For example, the "delay time gap" between RCM and TRM in the effective solution of the shortest delay time is calculated as follows: $(3350-3313.2) / 3350 * 100 \%=+1.11 \%$.

TABLE 11: Comparison of flight delays between RCM and TRM.

\begin{tabular}{lccccccccccc}
\hline & \multicolumn{2}{c}{$\begin{array}{c}\text { Delay time } \\
<5 \text { min }\end{array}$} & \multicolumn{2}{c}{$\begin{array}{c}\text { Delay time } \\
<10 \text { min }\end{array}$} & \multicolumn{2}{c}{$\begin{array}{c}\text { Delay time } \\
<15 \text { min }\end{array}$} & \multicolumn{2}{c}{$\begin{array}{c}\text { Delay time } \\
>20 \text { min }\end{array}$} & \multicolumn{2}{c}{$\begin{array}{c}\text { Delay time } \\
>30 \text { min }\end{array}$} \\
& RCM & TRM & RCM & TRM & RCM & TRM & RCM & TRM & RCM & TRM \\
\hline Number of flights & $\mathbf{5 6}$ & $\mathbf{1 6}$ & 103 & 78 & 129 & 108 & 64 & 62 & 31 & 37 \\
Percentage (\%) & $\mathbf{2 6 . 0 5}$ & $\mathbf{7 . 4 4}$ & 47.91 & 36.28 & 60.00 & 50.23 & 29.77 & 28.84 & 14.42 & 17.21 \\
\hline
\end{tabular}

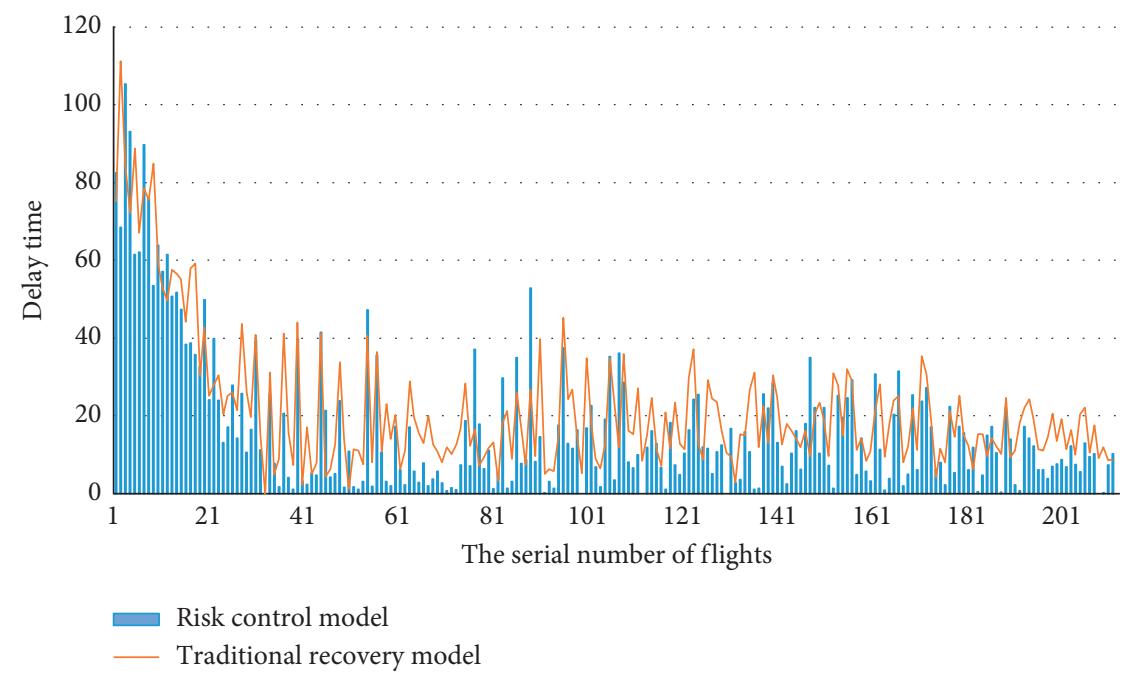

FIgURE 14: Comparison of flight delay time after optimization of two methods.

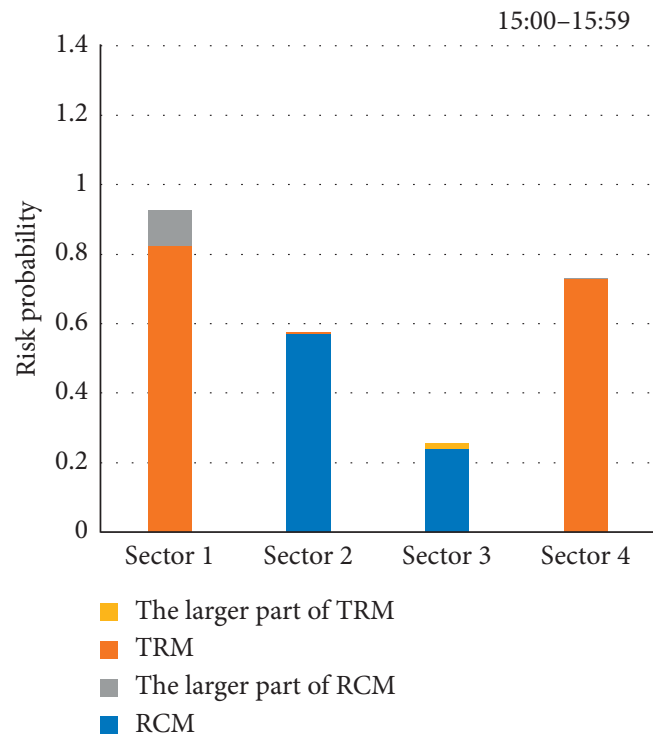

(a)

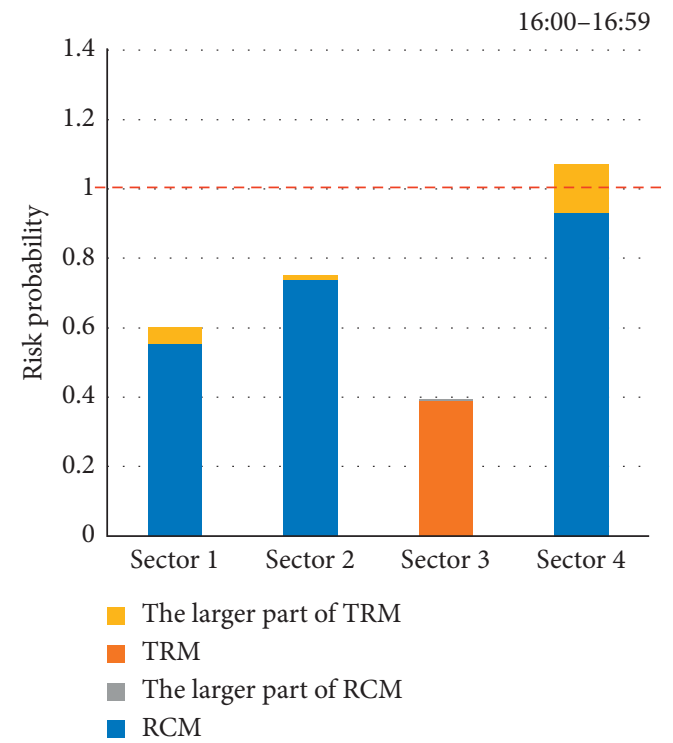

(b)

FIGURE 15: Comparison about risk probability of airspace control in each sector after optimization. 


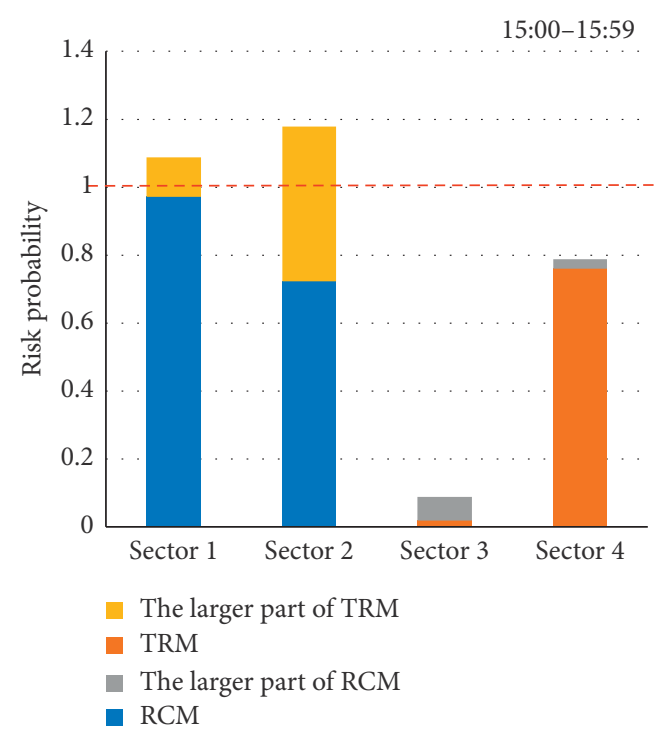

(a)

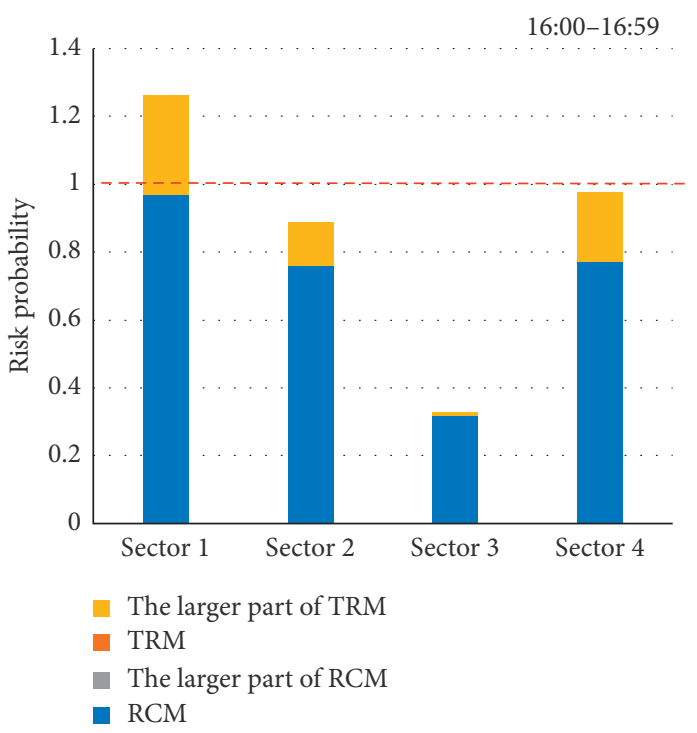

(b)

FIGURE 16: Comparison about risk probability of flight conflict of each sector after optimization.

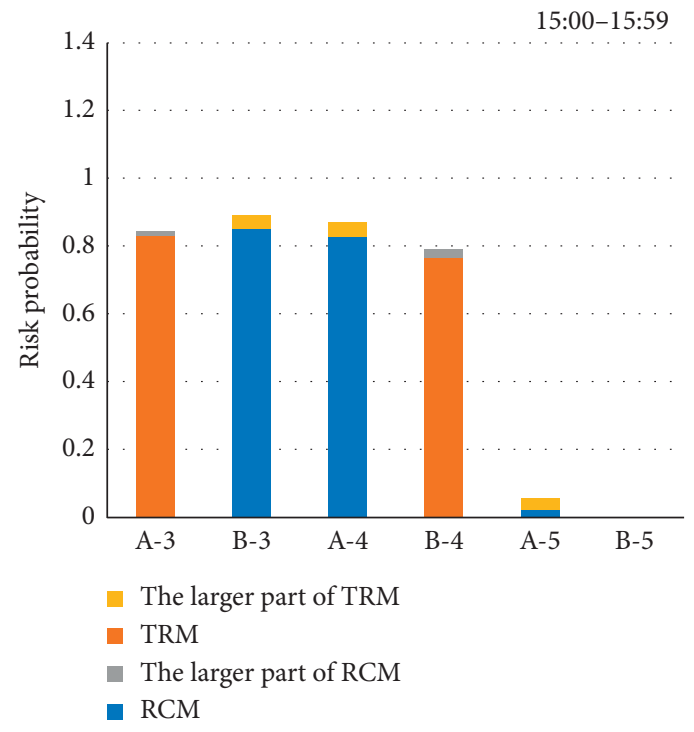

(a)

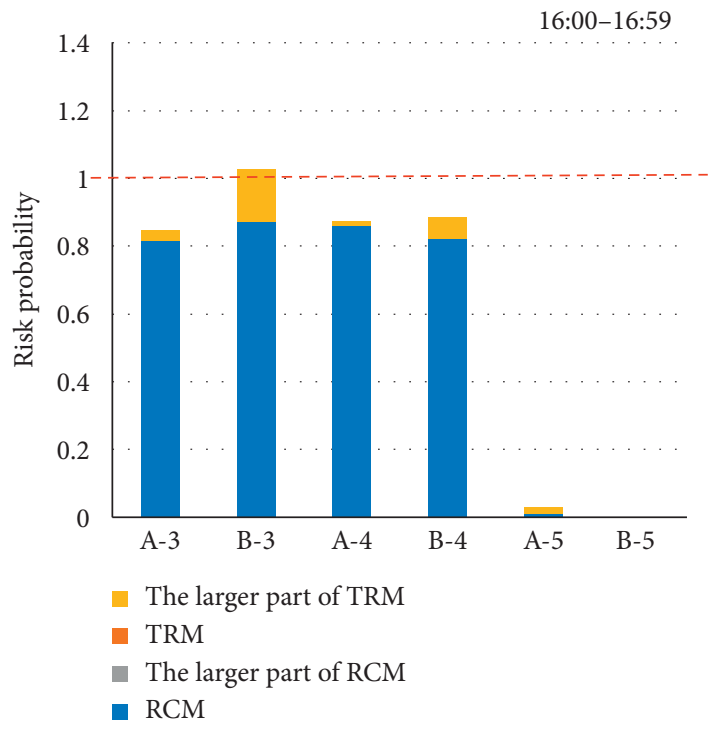

(b)

FIGURE 17: Comparison of risk probabilities of ground support, ground control, and taxiing conflict in each airport after optimization.

improvement of the security level of each risk node of the system.

\section{Conclusions}

Based on the quantitative assessment method of key risk points, this paper proposes a regional multiairport abnormal flight recovery method based on risk control and establishes a multiobjective mathematical model to minimize delay time and risk probability. Furthermore, the data of a typical multiairport system and MSINS (multistart algorithm with intelligent neighborhood selection) are used to compare the risk control model with the traditional recovery model. Based on this process, the following conclusions can be drawn.

(1) There are some hidden dangers in the traditional recovery methods of flight delay. Flight conflict and apron support are the risk points that need to be controlled most in the multiairport system. (2) A set of effective solutions can be obtained by using the algorithm. Taking the delay time as the optimal decision condition, the RCM (risk control model) can reduce the operation risk of the system and ensure that the delay time is basically unchanged. (3) Taking the risk probability as the optimal decision condition, the risk 


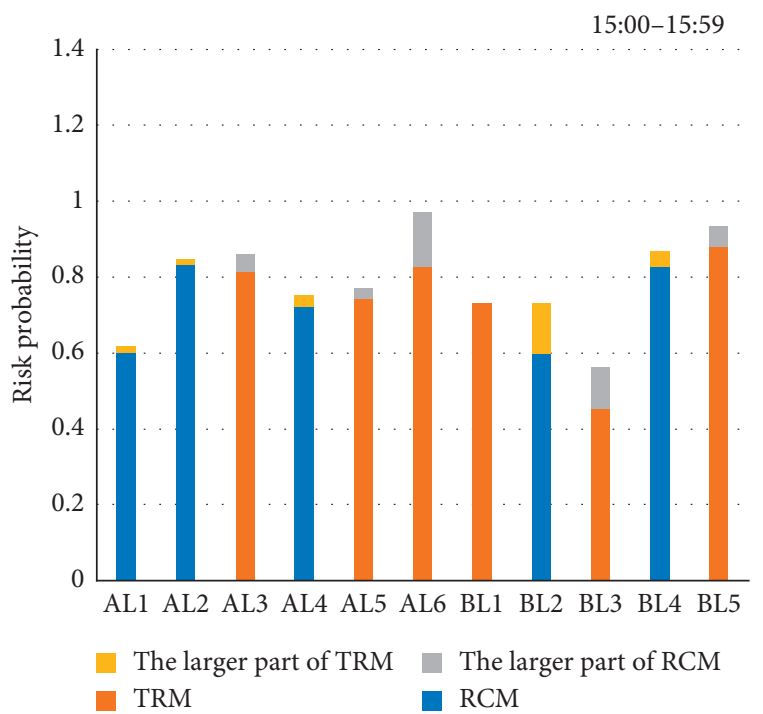

(a)

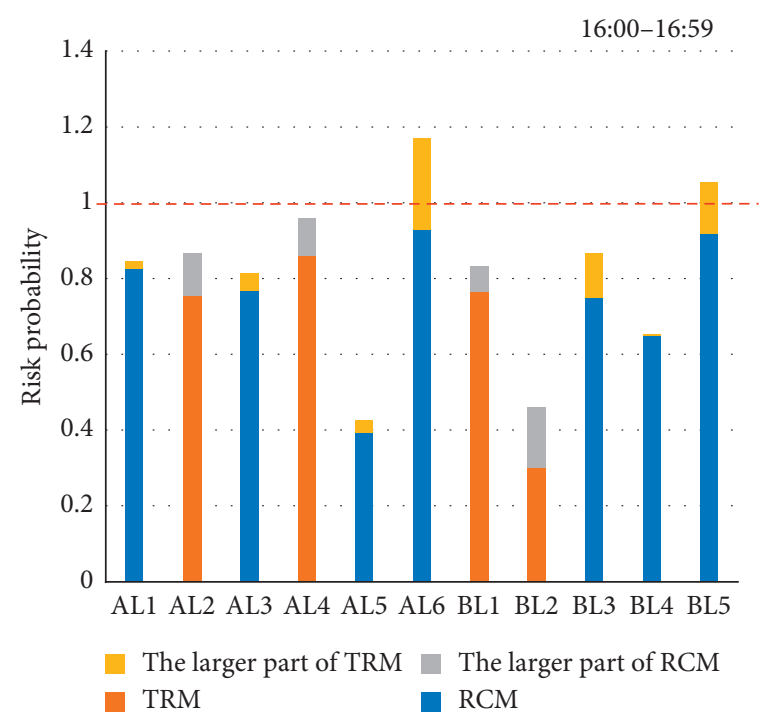

(b)

FIGURE 18: Comparison of risk probability of apron support in each airport after optimization.

control model can not only reduce the operation risk of the system but also reduce the flights' delay time. The number of flights with delay time less than 5 minutes obtained by RCM is $26.05 \%$, which is more than 3 times that of the TRM (traditional recovery model), which can save considerable recovery cost for airlines. Therefore, compared with the TRM, RCM can optimize the resource allocation of the regional multiairport system, especially flight conflicts and apron support, and improve the security level of the system while improving the recovery efficiency. The RCM is more in line with the operational requirements.

Regional multiairport system is the main mode of airport operation in the future, and this method has high practical application value. At the same time, the idea of flight recovery based on risk control can also be applied to aircraft recovery problems, integrated recovery, and other issues. Because there are many uncertain factors in the flight recovery problem, we plan to consider the uncertainty in the model in the future research and optimize the algorithm for this kind of multiobjective nonlinear optimization problem to improve the robustness.

\section{Data Availability}

The data generated and analyzed during the current study are available from the corresponding author on reasonable request.

\section{Conflicts of Interest}

The authors declare that there are no conflicts of interest regarding the publication of this paper.

\section{Acknowledgments}

This work was supported by the National Key R\&D Program of China (grant no. 2018YFC0809500), the National Natural
Science Foundation of China (grant nos. 71874081 and 71573122), and the Fundamental Research Funds for the Central Universities in NUAA (grant no. kfjj20190713).

\section{Supplementary Materials}

Table 1 provides specific information on delayed flights mentioned in Section 4.1, which is important data for the experimental scenario. Delays in flights $1-32$ due to bad weather from the previous period have been delayed until 15: 00 . During the study period (15:00-16:59), a total of 215 flights needed to be resumed. Airport A is predicted to have 55 approach flights and 63 departure flights. Airport B is predicted to have 39 approach flights and 58 departure flights. For example, the following information can be obtained for the first flight: the flight is a departure flight parked on Apron BL4. The aircraft is medium-sized. The flight is expected to take off from runway 4 of $B$ airport and pass through sector 2 and departure point DF1. (Supplementary Materials)

\section{References}

[1] X. S. Cao and W. Liao, "Regional spatial pattern and type classification of global multi-airport," Progress in Geography, vol. 37, no. 11, pp. 1473-1484, 2018.

[2] D. Teodorović and S. Guberinić, "Optimal dispatching strategy on an airline network after a schedule perturbation," European Journal of Operational Research, vol. 15, no. 2, pp. 178-182, 1984.

[3] J. M. Cao and A. Kanafani, "Real-time decision support for integration of airline flight cancellations and delays part I: mathematical formulation," Transportation Planning and Technology, vol. 20, no. 3, pp. 183-199, 1997.

[4] J. M. Cao and A. Kanafani, "Real-time decision support for integration of airline flight cancellations and delays part II: algorithm and computational experiments," Transportation Planning and Technology, vol. 20, no. 3, pp. 201-217, 1997. 
[5] M. F. Argüello, J. F. Bard, and G. Yu, "A GRASP for aircraft routing in response to groundings and delays," Journal of Combinatorial Optimization, vol. 1, no. 3, pp. 211-228, 1997.

[6] J. M. Rosenberger, E. L. Johnson, and G. L. Nemhauser, "Rerouting aircraft for airline recovery," Transportation Science, vol. 37, no. 4, pp. 408-421, 2003.

[7] N. Eggenberg, M. Salani, and M. Bierlaire, "Constraint-specific recovery network for solving airline recovery problems," Computers \& Operations Research, vol. 37, no. 6, pp. 10141026, 2010.

[8] S. Bisaillon, J.-F. Cordeau, G. Laporte, and F. Pasin, “A large neighbourhood search heuristic for the aircraft and passenger recovery problem," 4OR, vol. 9, no. 2, pp. 139-157, 2011.

[9] Z. Liang, F. Xiao, X. Qian et al., "A column generation-based heuristic for aircraft recovery problem with airport capacity constraints and maintenance flexibility," Transportation Research Part B: Methodological, vol. 113, pp. 70-90, 2018.

[10] J. D. Petersen, G. Sölveling, J.-P. Clarke, E. L. Johnson, and S. Shebalov, "An optimization approach to airline integrated recovery," Transportation Science, vol. 46, no. 4, pp. 482-500, 2012.

[11] K. Sinclair, J.-F. Cordeau, and G. Laporte, "Improvements to a large neighborhood search heuristic for an integrated aircraft and passenger recovery problem," European Journal of Operational Research, vol. 233, no. 1, pp. 234-245, 2014.

[12] D. Zhang, C. Yu, J. Desai, and H. Y. K. H. Lau, "A mathheuristic algorithm for the integrated air service recovery," Transportation Research Part B: Methodological, vol. 84, pp. 211-236, 2016.

[13] N. L. Kleinman, S. D. Hill, and V. A. Ilenda, "SPSA/SIMMOD optimization of air traffic delay cost," in Proceedings of the 1997 American Control Conference (Cat. No. 97CH36041), vol. 2, pp. 1121-1125, Albuquerque, NM, USA, June 1997.

[14] A. P. Saraf, J. P. Clarke, and E. Mclain, "Discussion and comparison of metroplex-wide arrival scheduling algorithms," in Proceedings of the 10th AIAA Aviation Technology, Integration, and Operations (ATIO) Conference, Fort Worth, TX, USA, September 2010.

[15] B. J. Capozzi, S. C. Atkins, and S. Choi, "Towards optimal routing and scheduling of metroplex operations," in Proceedings of the 9th AIAA Aviation Technology, Integration, and Operations Conference (ATIO), Hilton Head, South Carolina, USA, 2009.

[16] Z. Y. Zhou, Research on Coordinated Sequencing for Arrival and Departure in Chengdu Terminal Area, College of Air Traffic Management, Civil Aviation Flight University of China, Chengdu, China, 2018.

[17] J. F. Zhang, T. T. Ge, and Z. X. Zheng, "Collaborative arrival and departure sequencing for multi-airport terminal area," Journal of Transportation Systems Engineering and Information Technology, vol. 17, no. 2, pp. 197-204, 2017.

[18] Y. Y. Ma, M. H. Hu, J. N. Yin et al., "Collaborative sequencing and scheduling method for arrival and departure traffic flow in multi-airport terminal area," Acta Aeronautica et Astronautica Sinica, vol. 38, no. 2, pp. 225-237, 2017.

[19] Z. Wang and Y. Wu, "Collaborative aircrafts scheduling strategy in metroplex terminal area based on FS-MOPSO," Journal of Southwest Jiaotong University, vol. 52, no. 1, pp. 179-185, 2017.

[20] N. Mao, The Influence of Mental Fatigue Caused by Continuous Cognitive Operation on Risky and Uncertainty Decision Making, Department of Medical Psychology, Fourth Military Medical University, Xi'an, China, 2017.
[21] Y. Xue, J. X. Wang, and Y. W. Li, "Study on common causes of flight delays and risks based on Bayesian network," Aeronautical Computing Technique, vol. 45, no. 1, pp. 48-51, 2015.

[22] D. J. Wu, "A new method to assess airspace capacity based on controller workload," Journal of Wuhan University of Technology (Transportation Science \& Engineering), vol. 38, no. 4, pp. 846-849, 2014.

[23] S. Y. Yang, Research on Evaluation of Sector Capacity Base on Multi-Sector Coupling Operation, College of Civil Aviation, Nanjing University of Aeronautics and Astronautics, Nanjing, China, 2015.

[24] S. P. Wang and X. F. Zhou, "Area sector capacity assessment based on controller workload," Aeronautical Computing Technique, vol. 45, no. 4, pp. 116-118, 2015.

[25] Y. Yang, Research on Safety Assessment of Airspace Planning Based on PBN, College of Civil Aviation, Nanjing University of Aeronautics and Astronautics, Nanjing, China, 2015.

[26] L. Yang, Research on Optimization Techniques of Airport Surface Operation, College of Civil Aviation, Nanjing University of Aeronautics and Astronautics, Nanjing, China, 2012.

[27] J. Molina, A. D. López-Sánchez, A. G. Hernández-Díaz, and I. Martínez-Salazar, “A multi-start Algorithm with Intelligent Neighborhood Selection for solving multi-objective humanitarian vehicle routing problems," Journal of Heuristics, vol. 24, no. 2, pp. 111-133, 2018.

[28] J. Molina, M. Laguna, R. Martí, and R. Caballero, "SSPMO: a scatter tabu search procedure for non-linear multiobjective optimization," Informs Journal on Computing, vol. 19, no. 1, pp. 91-100, 2007.

[29] M. T. Shi, J. F. Zhang, T. T. Ge et al., "A combined arrival and departure scheduling for multi-airport system," Transactions of Nanjing University of Aeronautics and Astronautics, vol. 34, no. 5, pp. 578-585, 2017.

[30] C. X. Liao, Design and Implementation of Airport Ground Capacity Evaluation System, University of Electronic Science and Technology of China, Sichuan, China, 2008. 